OPEN ACCESS

Edited by:

Akio Kanai,

Keio University, Japan

Reviewed by:

Tohru Yoshihisa,

University of Hyogo, Japan John P. Hagan,

University of Texas Health Science

Center at Houston, United States

Yuka W. Iwasaki,

Keio University, Japan

${ }^{*}$ Correspondence: Kozo Tomita

kozo_tomita@cbms.k.u-tokyo.ac.jp; kozo-tomita@edu.k.u-tokyo.ac.jp

Specialty section:

This article was submitted to

$R N A$,

a section of the journal

Frontiers in Genetics

Received: 10 July 2018 Accepted: 24 October 2018 Published: 12 November 2018

Citation:

Yashiro Y and Tomita K (2018) Function and Regulation of Human

Terminal Uridylyltransferases.

Front. Genet. 9:538.

doi: $10.3389 /$ fgene.2018.00538

\section{Function and Regulation of Human Terminal Uridylyltransferases}

\author{
Yuka Yashiro and Kozo Tomita*
}

Department of Computational Biology and Medical Sciences, Graduate School of Frontier Sciences, The University of Tokyo, Kashiwa, Japan

RNA uridylylation plays a pivotal role in the biogenesis and metabolism of functional RNAs, and regulates cellular gene expression. RNA uridylylation is catalyzed by a subset of proteins from the non-canonical terminal nucleotidyltransferase family. In human, three proteins (TUT1, TUT4, and TUT7) have been shown to exhibit template-independent uridylylation activity at 3'-end of specific RNAs. TUT1 catalyzes oligo-uridylylation of U6 small nuclear (sn) RNA, which catalyzes mRNA splicing. Oligo-uridylylation of U6 snRNA is required for U6 snRNA maturation, U4/U6-di-snRNP formation, and U6 snRNA recycling during mRNA splicing. TUT4 and TUT7 catalyze mono- or oligo-uridylylation of precursor let-7 (pre-let-7). Let-7 RNA is broadly expressed in somatic cells and regulates cellular proliferation and differentiation. Mono-uridylylation of pre-let- 7 by TUT4/7 promotes subsequent Dicer processing to up-regulate let-7 biogenesis. Oligouridylylation of pre-let-7 by TUT4/7 is dependent on an RNA-binding protein, Lin28. Oligo-uridylylated pre-let-7 is less responsive to processing by Dicer and degraded by an exonuclease DIS3L2. As a result, let-7 expression is repressed. Uridylylation of prelet-7 depends on the context of the $3^{\prime}$-region of pre-let-7 and cell type. In this review, we focus on the $3^{\prime}$ uridylylation of U6 snRNA and pre-let-7, and describe the current understanding of mechanism of activity and regulation of human TUT1 and TUT4/7, based on their crystal structures that have been recently solved.

Keywords: terminal uridylyltransferase, TUTase, TUT1, TUT4/7, U6 snRNA, let-7, biogenesis, splicing

\section{INTRODUCTION}

Modification of the $3^{\prime}$-end of RNA by template-independent nucleotide addition is a posttranscriptional modification that plays important regulatory roles in gene expression. A well-known example of $3^{\prime}$-end modification is the addition of CCA to the $3^{\prime}$-end of tRNA at positions 74-76 by CTP:(ATP)-tRNA nucleotidyltransferase (CCA-adding enzyme) and related enzymes (Deutscher, 1990; Tomita and Weiner, 2001, 2002; Weiner, 2004). CCA-addition to the $3^{\prime}$-end of tRNA is required for amino acid attachment to the $3^{\prime}$-terminus of tRNA by aminoacyl-tRNA synthetases (Sprinzl and Cramer, 1979), and also for peptide bond formation on the ribosome (Green and Noller, 1997; Kim and Green, 1999; Nissen et al., 2000). Further, CCA-addition to the $3^{\prime}$-end of tRNA is involved in the quality control of dysfunctional tRNAs. Dysfunctional tRNA molecule with

Abbreviations: CM, catalytic module; CPSF, cleavage and polyadenylation specificity factor; dsRNA, double-stranded RNA; ISL, internal stem-loop; KA-1, kinase associated-1; LIM, Lin28-interacting module; miRNA, microRNA; PAP, poly(A) polymerase; RRM, RNA recognition motif; snRNA, small nuclear RNA; snRNP, small nuclear ribonucleoprotein; TUTase, terminal uridylyltransferase; ZF, zinc finger; ZK, zinc knuckle. 
an unstable acceptor stem is modified by CCACCA addition, and the CCACCA tail serves as a degradation signal for cellular RNA decay machinery (Wilusz et al., 2011; Betat and Morl, 2015; Kuhn et al., 2015). Another well-known example of template-independent nucleotide addition to the $3^{\prime}$-end of RNA is polyadenylation of mRNA by a canonical PAP. Polyadenylation of mRNA regulates mRNA stability, mRNA export from the nucleus to cytoplasm, and translation initiation in eukaryotes (Beelman and Parker, 1995; Sachs et al., 1997; Wahle and Rüegsegger, 1999; Edmonds, 2002; Moore and Proudfoot, 2009). Polyadenylation of mRNA also regulates degradation of mRNA in eubacteria (Carpousis et al., 1999; Dreyfus and Régnier, 2002; Régnier and Hajnsdorf, 2009).

Detailed mechanism of polyadenylation by canonical PAPs (Bard et al., 2000; Martin et al., 2000; Balbo and Bohm, 2007), and that of CCA-addition by CCA-adding enzymes and related enzymes have been clarified in the last two decades (Li et al., 2002; Okabe et al., 2003; Xiong et al., 2003; Tomita et al., 2004, 2006; Xiong and Steitz, 2004, 2006; Toh et al., 2008, 2009, 2011; Pan et al., 2010; Tomita and Yamashita, 2014; Yamashita et al., 2014, 2015; Yamashita and Tomita, 2016). However, a new family of PAPs, non-canonical PAPs, have emerged, with the fission yeast cytoplasmic PAP, Cid1, first identified as a non-canonical PAP (Wang et al., 2000), which was later revealed to be a terminal uridylyltransferase (Rissland et al., 2007). Non-canonical PAPs are conserved and play important roles in gene expression in various eukaryotes, from yeast to human (Stevenson and Norbury, 2006; Norbury, 2010; Scott and Norbury, 2013; Lee et al., 2014; De Almeida et al., 2018). Phylogenetic distribution of non-canonical PAPs in eukaryotes has recently described (Chang et al., 2018). The family of proteins share the catalytic domain with canonical PAPs but contain different ribonucleotide base recognition motifs (Martin and Keller, 2007). As a result, some of the non-canonical PAPs bearing histidine insertion in the ribonucleotide base recognition motif use UTP as a substrate and function as TUTases (Kwak and Wickens, 2007; Rissland et al., 2007; Mullen and Marzluff, 2008; Wickens and Kwak, 2008).

Various classes of RNAs, including mRNA, miRNA and snRNA, are uridylylated by non-canonical terminal nucleotidyltransferase family of enzymes. In Trypanosome mitochondria, uridylylation is required for guide RNA maturation (Aphasizhev et al., 2016). Uridylylation is also important for regulation of small RNA expression. In Drosphila melanogaster, a TUTase named Tailor prevents biogenesis of mirtron (Bortolamiol-Becet et al., 2015; Reimao-Pinto et al., 2015; Rissland, 2015), while uridylation serves as a degradation marker for small RNAs in various organisms (De Almeida et al., 2018). In addition, uridylylation also facilitates mRNA decay. Uridylylation-mediated mRNA degradation contributes to cellular mRNA metabolism and also is involved in maternal mRNA clearance during maternal to zygotic transition (Scott and Norbury, 2013; Lee et al., 2014; Lim et al., 2014; Morgan et al., 2017; Chang et al., 2018). Thus, uridylylation of RNA $3^{\prime}$-ends plays a pivotal role in the biogenesis and metabolism of functional RNAs, facilitating regulation of gene expression. The detailed functions of uridylylation were recently reviewed (De Almeida et al., 2018; Menezes et al., 2018).
In human, seven non-canonical nucleotidyltransferases have been identified, with diverse cellular functions (Stevenson and Norbury, 2006; Martin and Keller, 2007; Wilusz and Wilusz, 2008). In this review, we use the updated HUGO-approved nomenclature to refer those enzymes, as HUGO-approved gene symbols for those non-canonical terminal nucleotidyltransferases have been recently changed (Figure 1). Among the seven human non-canonical terminal nucleotidyltransferases, four enzymes show adenylyltransferase activity. MTPAP is a mitochondorial PAP, which regulates stability of mitochondrial mRNAs (Tomecki et al., 2004; Nagaike et al., 2005). TENT2 adenylates selected mRNAs and miRNAs in cytoplasm (Kwak et al., 2004; Nagaike et al., 2005; Katoh et al., 2009; Glahder and Norrild, 2011; D'Ambrogio et al., 2012), while TENT4A and TENT4B add poly(A) to various classes of nuclear RNAs and involve in RNA degradation as a subunit of a TRAMP-like complex (Berndt et al., 2012; Ogami et al., 2013; Sudo et al., 2016). TENT4A and TENT4B have also recently been shown to be responsible for mRNA guanylylation (Lim et al., 2018).

The other three enzymes (TUT1, TUT4, and TUT7) are the TUTases that mediate template-independent uridylylation at the $3^{\prime}$-end of RNAs in the human cells. TUT1 is a nuclear TUTase and required for maturation process of the $3^{\prime}$-end of U6 snRNA (Scott and Norbury, 2013; Lee et al., 2014; Lim et al., 2014). On the other hand, TUT4 and TUT7 mainly localize in cytoplasm, and they are involved in various cellular processes, including regulation of miRNA biogenesis, surveillance for defective noncoding RNAs, replication dependent decay of poly(A)- histone mRNAs, and degradation of poly(A) + mRNAs (De Almeida et al., 2018; Menezes et al., 2018). In addition to those regulatory roles, TUT4 and TUT7 are also reported to uridylylate viral RNAs and LINE-1 mRNAs and act as immune system against genomic invasion (Le Pen et al., 2018; Warkocki et al., 2018; Yeo and Kim, 2018).

Recently, the crystal structures of human TUTases, TUT1 and TUT7, have been reported, and together with the biochemical studies of these enzymes, the molecular bases of uridylylation of $3^{\prime}$-end of specific RNAs have been proposed (Faehnle et al., 2017; Yamashita et al., 2017). In the current review, we describe the molecular mechanism and regulation of uridylylation of specific RNAs by human TUT1 and TUT7, based on their structures.

\section{TUT1: OLIGOURIDYLYLATION OF U6 snRNA}

\section{Biogenesis of U6 snRNA}

Pre-mRNA splicing in eukaryotes is catalyzed by the spliceosome composed of five small ribonucleoprotein complexes (U1, U2, U4, U5, and U6 snRNPs) and a large number of proteins (Will and Luhrmann, 2011). U6 snRNP is composed of U6 snRNA, p110 (hPrp24), and heteroheptameric Lsm2-8 ring proteins. Proteins p110 and Lsm2-8 promote the annealing of U6 and U4 snRNAs for U4/U6 di-snRNP formation (Jandrositz and Guthrie, 1995; Raghunathan and Guthrie, 1998; Achsel et al., 1999). U5 snRNP joins the U4/U6 di-snRNP to form U4/U6•U5 tri-snRNP. The U4/U6•U5 tri-snRNP is recruited to the pre-spliceosome, composed of pre-mRNA, and U1 and U2 snRNPs. U6 snRNA 


\section{TUT1 (TENT1/PAPD2) \\ TENT2 (PAPD4/GLD2) \\ Catalytic motif \\ \ulcorner \\ TUT4 (TENT3A/PAPD3/ZCCHC11) \\ TUT7 (TENT3B/PAPD6/ZCCHC6)

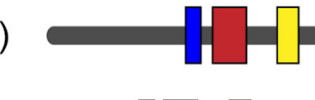 \\ 는 \\ 874 aa \\ $\square=$ \\ 484 aа

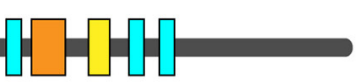 \\ 1640 aa

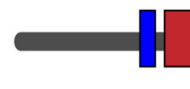 \\ 느물 \\ 1495 aa \\ TENT4A (PAPD7/POLS/TRF4-1) \\ thi \\ 542 aa \\ TENT4B (PAPD5/TRF4-2) \\ MTPAP (TENT6/PAPD1)

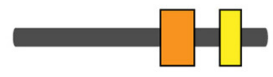 \\ 489 aa \\ 582 aa}

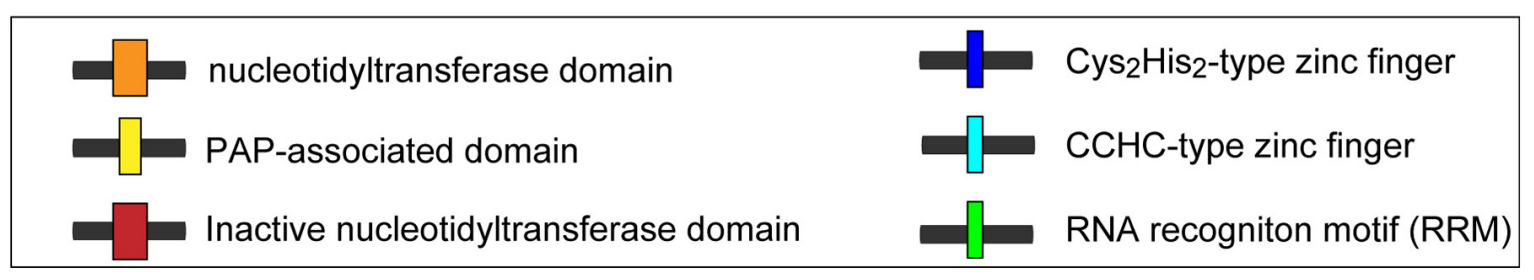

FIGURE 1 | Human non-canonical terminal nucleotidyltransferases. Schematic representation of domain organization of seven human non-canonical terminal nucleotidyltransferases. The catalytic motif is composed of nucleotidyltransferase domain (orange box) and PAP-associated domain (yellow box). Inactive nucleotidyltransferase domains are designated by red boxes. $\mathrm{C}_{2} \mathrm{H}_{2}$-type zinc finger and $\mathrm{CCHC}$ zinc finger domains are designated as dark blue and light blue boxes, respectively. RNA recognition motif (RRM), is shown as a green box. The figure is modified from Heo et al. (2009) and Lee et al. (2014).

forms an alternative helix with the U2 snRNA, following which two-step splicing reaction proceeds, accompanying the structural rearrangements of U6 snRNA in the spliceosome. In base-paired U6-U2 snRNAs, U6 snRNA participates in active-site formation and divalent cation coordination for the catalysis of splicing (Fica et al., 2013).

U6 snRNA is transcribed by RNA polymerase III and undergoes multiple maturation processes (Wilusz and Wilusz, 2013). The U6 snRNA transcript has a $5^{\prime}$-stem, ISL, and telestem secondary structures (Rinke and Steitz, 1985; Karaduman et al., 2006; Figure 2A). The U6 snRNA primary transcript contains four genome-encoded $3^{\prime}$-end uridines (U4-OH) (Figure 2B). After transcription, the $3^{\prime}$-end is oligo-uridylylated by TUT1 (Trippe et al., 1998; Trippe et al., 2006). Then, the oligouridylylated tail of U6 snRNA is trimmed by a $3^{\prime}-5^{\prime}$ exonuclease, Mpn1 (Usb1) (Mroczek et al., 2012; Shchepachev et al., 2012; Hilcenko et al., 2013). The $3^{\prime}$-end of the mature U6 snRNA has five uridines capped with a $2^{\prime}, 3^{\prime}$-cyclic phosphate $(\mathrm{U} 4-\mathrm{U}>\mathrm{p})$, which protects U6 snRNA from degradation.

The oligo-uridylylated tail of U6 snRNA is the binding site for the Lsm2-8 complexes (Achsel et al., 1999; Vidal et al., 1999); for the annealing of U6 and U4 snRNAs to form di-U4/U6 snRNP; and for the recycling of U6 snRNA after the splicing reaction (Bell et al., 2002). Thus, $3^{\prime}$-oligo-uridylylation of U6 snRNA by TUT1 contributes to efficient pre-mRNA splicing in cells. Human TUT1 was originally identified as a U6 snRNA-specific TUTase (Trippe et al., 2003; Trippe et al., 2006). Subsequently, it was also reported that TUT1 can function as a PAP acting with specific mRNAs under specific conditions (Mellman et al., 2008).

\section{Structure of Human TUT1}

Recently, the crystal structures of human TUT1, and its complexes with UTP or ATP have been reported (Yamashita et al., 2017). These were the first structures of a TUTase from a higher eukaryote. Human TUT1 is a multi-domain protein composed of an N-terminal ZF, N-terminal RRM, a catalytic motif in the middle, and an uncharacterized C-terminal domain (Trippe et al., 2006). The catalytic motif is composed of nucleotidyltransferase domain and PAP-associated domain (Figure 1). Since crystals of full-length human TUT1 protein could not be obtained, truncated forms of TUT1 protein were crystallized and their structures were determined.

TUT1 (TUT1_delN), lacking N-terminal ZF and RRM, consists of three domains: the catalytic palm and finger domains, and an additional distinct domain linked to the C-terminus of the protein (Figure 3A). The C-terminal region of TUT1 is the previously unidentified RNA-binding domain, named KA-1 domain. 

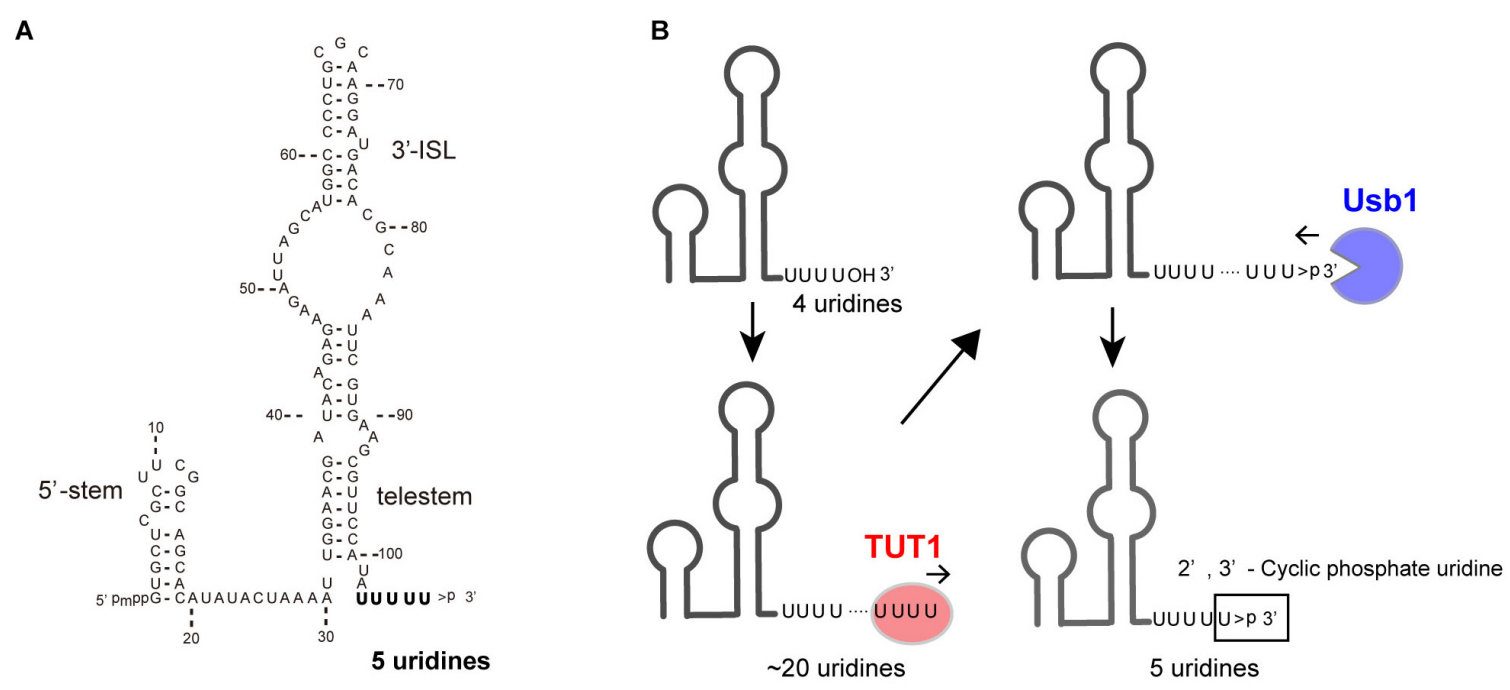

FIGURE 2 | TUT1 in the maturation process of human U6 snRNA. (A) Secondary structure of human mature U6 snRNA transcript. Mature U6 snRNA harbors $5^{\prime}-\gamma$-methyl tri-phosphate (5'-pmpp) and $2^{\prime}, 3^{\prime}$-cyclic phosphate (>p) at $5^{\prime}$ - and $3^{\prime}$-ends, respectively. (B) Maturation of U6 snRNA. Primary U6 snRNA transcript harbors four genome-encoded $3^{\prime}$-uridines (UUUUOH). The $3^{\prime}$-end is oligo-uridylylated by TUT1, with the addition of up to 20 uridines. Finally, oligo-uridylylated U6 snRNA is trimmed by Usb1. Mature U6 snRNA harbors five $3^{\prime}$-uridines capped with a $2^{\prime}, 3^{\prime}$-cyclic phosphate (UUUUU > p).

The overall structure of the catalytic core palm and finger domains of TUT1 shares topological homology with those of yeast Cid1 and vertebrate mitochondrial PAP (Bai et al., 2011; Lunde et al., 2012; Munoz-Tello et al., 2012; Yates et al., 2012; Lapkouski and Hallberg, 2015). The palm domain of human TUT1 consists of five-stranded $\beta$-sheets and two $\alpha$-helices, and three catalytic carboxylates (Asp216, Asp218, and Asp381). The structure of TUT1 palm domain shares homology with those of DNA polymerase $\beta$ family proteins (Aravind and Koonin, 1999). The finger domain has a helical structure with ten $\alpha$-helices and three $\alpha$-sheets, and is homologous to the central domain of PAP $\alpha$ (Bard et al., 2000; Martin et al., 2000). The incoming nucleotide is located in the cleft between the palm and fingers.

The C-terminal domain of TUT1 consists of four anti-parallel $\beta$-sheets and five $\alpha$-helices (Figure 3B). This domain shares topological homology with the KA-1 domain of various proteins (Moravcevic et al., 2010). Structure of another crystal form of TUT1_delN suggests that the KA-1 domain can rotate by approximately 40 degrees with respect to the catalytic core domains, using $\alpha 14$ as the axis of rotation (Figure 3C). In the TUT1 structure lacking C-terminal KA-1 and N-terminal ZF domains, the $\mathrm{N}$-terminal RRM adapts a typical RRM fold (Kenan et al., 1991), with four anti-parallel $\beta$-sheets stacked onto two $\alpha$-helices. The RRM is connected to the catalytic domain by a flexible linker (Figure 3A). Thus, the N-terminal RRM and ZF are mobile in the RNA substrate-free form of TUT1.

\section{Nucleotide Recognition by TUT1}

The structures of TUT1 in complex with either UTP or ATP have been reported (Figure 3D). Both UTP and ATP reside in the cleft between the palm and finger domains. In the structure of UTP-bound TUT1, the uracil base is sandwiched between Tyr432 and the side chain of $\mathrm{Arg} 366$. The $\mathrm{O}_{2}$ and $\mathrm{O}_{4}$ atoms of
UTP form hydrogen bonds with Asn392 and His549, respectively. The $\mathrm{N}_{3}$ atom of UTP forms a hydrogen bond with a water molecule that also forms a hydrogen bond with Asp543. In the ATP-bound structure, only the $\mathrm{N}_{1}$ atom of the adenine base of ATP forms a hydrogen bond with His549. The mechanism of nucleotide recognition by TUT1 and the specificity of TUT1 are essentially the same as those of yeast Cid1 (Lunde et al., 2012; Munoz-Tello et al., 2012; Yates et al., 2012). Human TUT1 incorporates UMP more efficiently than AMP into U6 snRNA transcript ending with four uridines. The steady-state kinetics of nucleotide incorporation into U6 snRNA indicate that UTP is a much better substrate of TUT1 than ATP (around 700-fold) (Yamashita et al., 2017).

\section{Domain Requirement for U6 snRNA Recognition by TUT1}

The structure of human TUT1-U6 snRNA complex is not yet available. However, recent biochemical studies using full-length and truncated human TUT1 variants suggest that U6 snRNA is recognized by multiple domains of TUT1 (Yamashita et al., 2017). Human TUT1 possesses additional domains compared with the yeast Cid1 structure. TUT1 is composed of N-terminal ZF, RRM, palm, finger, and KA-1 domains (Figures 1, 3A). The domain organization of TUT1 is also different from those of other human non-canonical terminal nucleotidyltransferase families, although the structures of catalytic domains are homologous (Stevenson and Norbury, 2006; Martin and Keller, 2007; Wilusz and Wilusz, 2008).

Steady-state kinetics revealed that human TUT1 variants lacking the $\mathrm{N}$-terminal $\mathrm{ZF}$ domain $(\Delta \mathrm{Z})$, lacking both the $\mathrm{ZF}$ and RRM domains, $(\Delta \mathrm{ZR})$, or lacking the KA-1 domain $(\Delta \mathrm{KA}-1)$ exhibit reduced uridylylation of U6 snRNA transcript. The $K_{\mathrm{m}}$ values of U6 snRNA for $\Delta \mathrm{Z}$ and $\Delta \mathrm{ZR}$ are ca. 5-folds higher than 
A

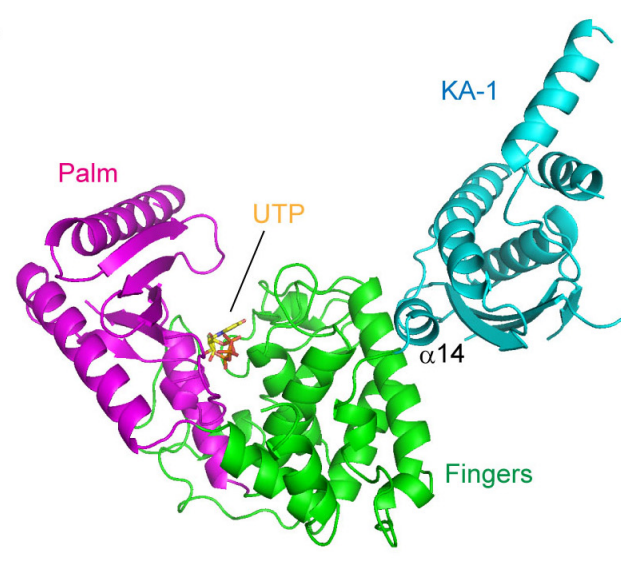

TUT1 wt

TUT1_deIN

C

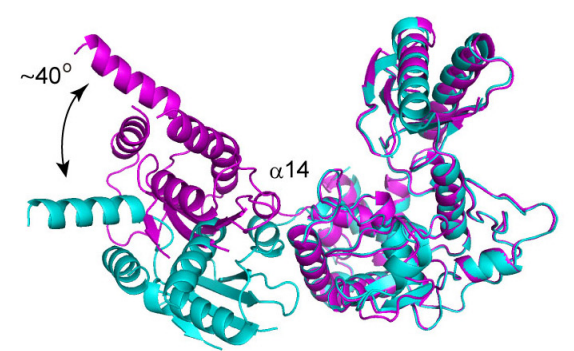

D

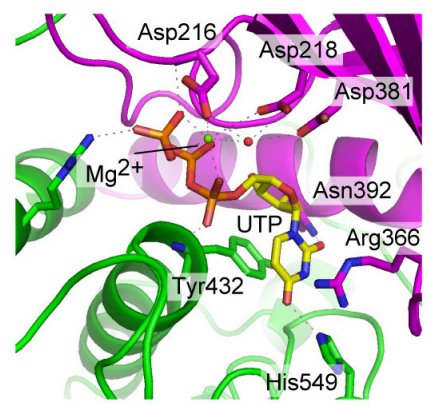

B
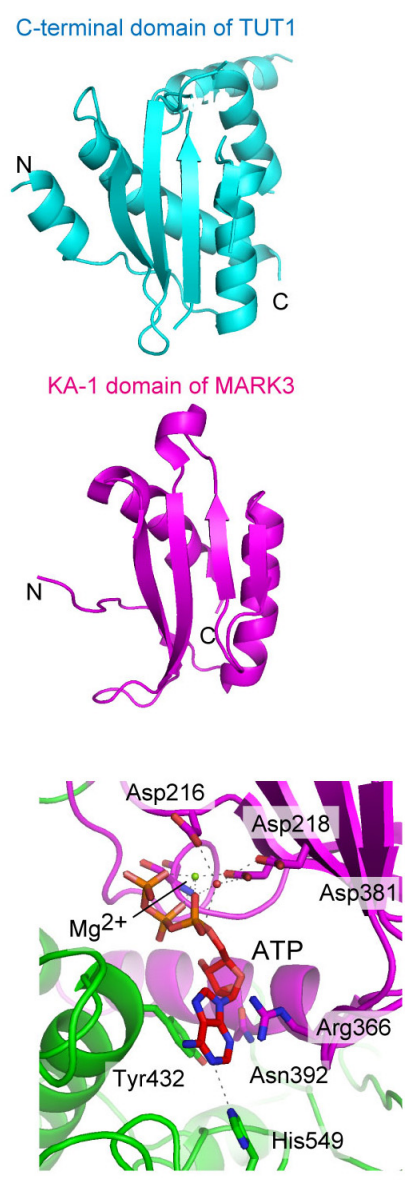

FIGURE 3 | Structure of human TUT1. (A) The overall structure of human TUT1 lacking N-terminal ZF and RRM (TUT1_deIN). Palm (magenta), fingers (green) and KA-1 (cyan). UTP (stick model in yellow) resides in the cleft between palm and finger domains. Inset, the overall structure of human TUT1 lacking C-terminal KA-1. The linker between RRM (orange) and palm domain is flexible. (B) KA-1 domain of TUT1 (upper, cyan) is homologous to KA-1 domain of MARK3 kinase (lower, pink). (C) Superposition of TUT1_delN structures of different forms of crystals. C-terminal KA-1 (cyan) domains of TUT1 are mobile and can rotate approximately 40 degrees relative to the catalytic domain, using $\alpha 14$ as the rotation axis. (D) Nucleotide recognition by human TUT1. UTP recognition (left) and ATP recognition (right). Nucleotides are depicted by stick models.

that for wild-type TUT1. The overall uridylylation efficiencies of $\Delta \mathrm{Z}$ and $\Delta \mathrm{ZR}$ are less than $0.2 \%$ that of wild-type TUT1, and their reduced activities are associated with reduced catalytic efficiencies. Thus, the N-terminal ZF and RRM domains might assist in the proper positioning of the $3^{\prime}$-end of U6 snRNA within the catalytic site for catalysis. The $K_{\mathrm{m}}$ value of U6 snRNA for $\triangle \mathrm{KA}-1$ is about 10 -folds higher than that of wild-type TUT1, and the overall uridylylation efficiency of $\triangle \mathrm{KA}-1$ is ca. $20 \%$ that of wild-type TUT1. Hence, the C-terminal KA-1 domain increases TUT1 affinity for U6 snRNA at the UMP-incorporation stage.

The KA-1 domain of TUT1 is conserved among vertebrates, with positively charged clusters on the KA-1 surface (Figure 4A). The KA-1 domain itself is able to bind RNA, and substitutions of positively charged amino acids in the KA-1 domain to alanine reduce or abolish the RNA-binding activity. Thus, the previously unidentified C-terminal domain, KA-1, is an RNAbinding domain involved in U6 snRNA recognition, together with the N-terminal ZF and RRM domains. The N-terminal RRM is mobile relative to the catalytic core domains, and the C-terminal KA-1 rotates relative to the catalytic core domains (Figures $3 \mathbf{A}, \mathbf{C}$ ). Thus, at the UMP-incorporation stage, the domain movements would be coupled with the recognition of $\mathrm{U} 6$ snRNA.

\section{Interaction Between TUT1 and U6 snRNA, and Oligo-Uridylylation}

TUT1 tightly interacts with U6 snRNA in vivo. The interactions between U6 snRNA and TUT1, and TUT1 truncated variants were recently analyzed by using $\mathrm{Tb}(\mathrm{III})$ hydrolysis mapping (Walter et al., 2000), and the protection patterns for U6 snRNA in the presence and absence of TUT1 protein and its variants were assessed. These studies demonstrated the TUT1 domain requirements for U6 snRNA recognition, as well as structural changes of U6 snRNA upon TUT1 binding. 
A

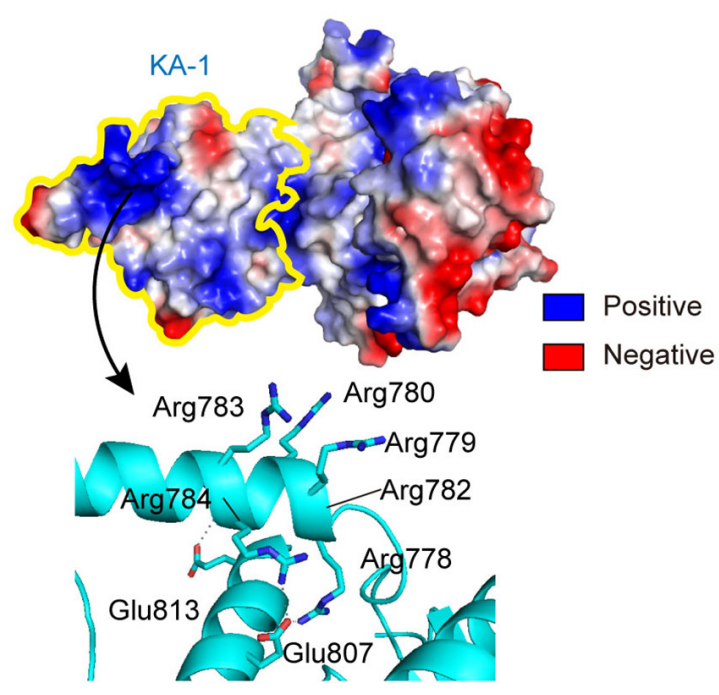

B

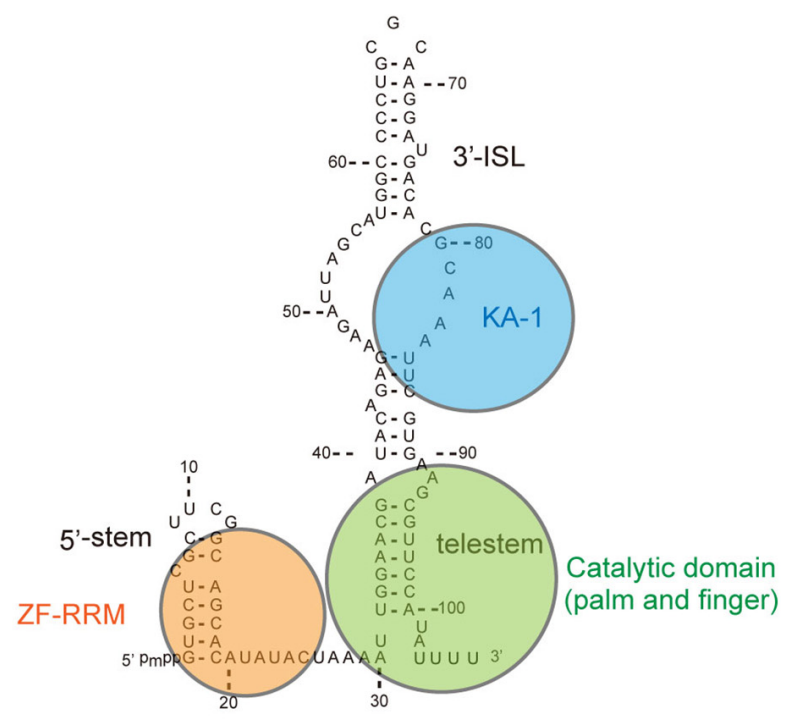

c mobile $k \cdots \cdots$
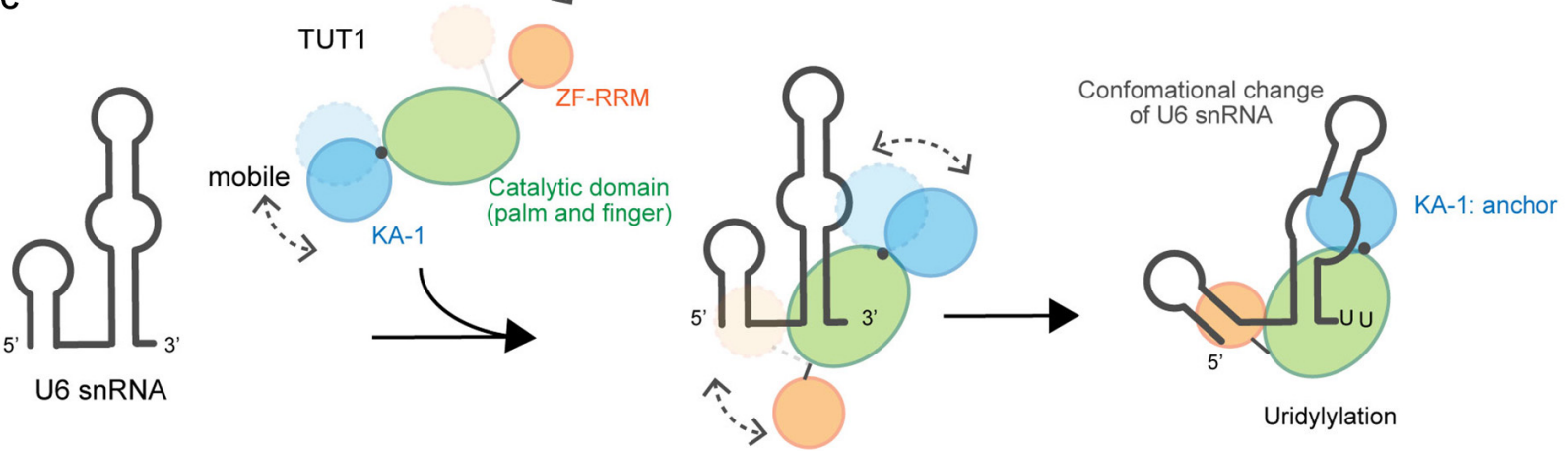

FIGURE 4 | Interactions between U6 snRNA and TUT1. (A) Electrostatic potential of KA-1 domain of human TUT1. Positively and negatively charged areas are colored blue and red, respectively. KA-1 domain is outlined by yellow line (upper), and harbors clusters of positively charged amino acids (below). (B) Multi-domain utilization by TUT1 for U6 snRNA oligo-uridylylation. Schematic representation of interactions between U6 snRNA and TUT1 analyzed by Tb(III) hydrolysis mapping. $\mathrm{N}$-terminal ZF and RRM (orange), catalytic palm and fingers (green), and C-terminal KA-1 (cyan). (C). Mechanism of oligo-uridylylation of U6 snRNA by TUT1. KA-1 and ZF-RRM are mobile. Binding of TUT1 to U6 snRNA induces conformational change of U6 snRNA, and KA-1 of TUT1 acts as an anchor during oligo-uridylylation. N-terminal ZF and RRM (orange), catalytic palm and fingers (green), and C-terminal KA-1 (cyan).

U6 snRNA is recognized by multiple domains of TUT1 (Figure 4B; Yamashita et al., 2017). The N-terminal ZF and RRM domains of TUT1 interact with the single-stranded $5^{\prime}$-end of U6 snRNA, and the KA-1 domain interacts with the bulging loops. The core catalytic domain binds tightly to the double-stranded telestem region, and the $3^{\prime}$-region of U6 snRNA remains singlestranded. Almost the entire U6 snRNA sequence is recognized by the mobile $\mathrm{N}$-terminal RNA-binding domain and the C-terminal KA-1 domain, cooperatively with the catalytic core domain. The recognition of U6 snRNA by TUT1 is coupled with domain movements and structural changes of U6 snRNA. In particular, interaction with TUT1 induces conformational changes in the $3^{\prime}$-ISL and the bulging loop of U6 snRNA.

The presence of $\mathrm{N}$-terminal and C-terminal RNA-binding domains prevents U6 snRNA from dislodging from the enzyme surface during uridylylation reaction (Figure 4C). The
C-terminal KA-1 of TUT1 might function as an anchor of the U6 snRNA molecule during oligo-uridylylation. TUT1 lacking C-terminal KA-1 or protein variants with substitutions of the positively charged residues in KA-1 (Figure 4A) add a relatively small number of UMPs ( -2 nts) compared with wild-type TUT1 ( -5 nts) (Yamashita et al., 2017). Absence of the KA-1 domain or loss of KA-1 RNA-binding activity would allow U6 snRNA to translocate easily on the enzyme surface. Following incorporation of several UMP molecules at the $3^{\prime}$-end of U6 snRNA by a series of open-to-closed conformation cycles of the catalytic domain (Munoz-Tello et al., 2014; Yates et al., 2015), the $3^{\prime}$ region of the oligo-uridylylated tail would be compressed within the active pocket of TUT1. Consequently, the $3^{\prime}$-end of U6 snRNA would no longer relocate to the active site. Finally, TUT1 terminates RNA synthesis and oligo-uridylylated U6 snRNA is released from the enzyme, as observed in the mechanism of RNA 
synthesis termination by tRNA nucleotidyltransferases (Tomita and Yamashita, 2014; Yamashita et al., 2014, 2015; Yamashita and Tomita, 2016).

\section{TUT1 Can Function as a PAP}

While TUT1 has been originally identified as a U6 snRNAspecific TUTase (Trippe et al., 1998, 2003, 2006), TUT1 also reportedly functions as a PAP, acting on specific mRNAs under oxidative stress conditions (Mellman et al., 2008). TUT1 interacts with phosphatidylinositol 4-phosphate 5-kinase I $\alpha$ (PIPKI $\alpha)$ and its PAP activity is also activated by phosphatidylinositol 4,5bisphosphate (PIns4,5P2) in vitro (Mellman et al., 2008; Mohan et al., 2015). Upon oxidative stress, TUT1 is recruited into the CPSF complex for the polyadenylation of specific oxidative-stress response mRNAs (Mellman et al., 2008; Laishram and Anderson, 2010). The PAP activity of TUT1 is also activated by several protein kinases (Gonzales et al., 2008; Laishram et al., 2011; Mohan et al., 2015).

The structure of TUT1-ATP complex revealed that the adenine base forms only one hydrogen bond with His549 (Figure 3D). Biochemical analysis indicated that TUT1 has a lower affinity for ATP than for UTP in vitro (Yamashita et al., 2017). The interaction of TUT1 with other factors and/or its phosphorylation by several kinases might promote CPSF complex formation at specific mRNAs. Since the KA-1 domain of MARK-3 binds to phospholipids (Moravcevic et al., 2010), the mobile KA-1 domain of TUT1 might interact with PIns4,5P2. This interaction might regulate the activity or localization of TUT1, and TUT1 recruitment to the CPSF complex might induce allosteric structural changes of TUT1 nucleotide-binding pocket to accommodate ATP. Thus, TUT1 might be able to add poly(A) tails to specific mRNAs under specific biological conditions.
Detailed mechanism of the alteration of the nucleotide specificity of TUT1 in specific biological processes awaits further study.

\section{TUT4 AND TUT7: URIDYLYLATION OF Pre-Let-7}

\section{Biogenesis of Let-7}

MiRNAs are small (21-25-nt) non-coding RNAs that function in gene silencing. Together with Argonaute proteins, miRNAs form RNA-induced silencing complex, and inhibit protein synthesis or induce mRNA degradation by base-pairing with target mRNAs (Braun et al., 2012). Let-7 is a highly conserved miRNA, from nematode to human, and is known to regulate various cellular processes (Bussing et al., 2008; Thornton and Gregory, 2012). It regulates cellular proliferation by acting as a tumor suppressor. It also regulates cellular differentiation, development, and apoptosis, and is involved in glucose metabolism (Reinhart et al., 2000; Houbaviy et al., 2003; Takamizawa et al., 2004; Johnson et al., 2005; Tsang and Kwok, 2008; Zhu et al., 2011).

The synthesis of most miRNAs begins with the transcription of a primary miRNA transcript (pri-miRNA) by RNA polymerase II. Then, pri-miRNA is cleaved to become precursor miRNA (premiRNA) by Drosha. Pre-miRNA is exported to the cytoplasm by Exportin-5. In the cytoplasm, pre-miRNA is further processed by Dicer to produce mature miRNA, which functions in gene silencing (Ha and Kim, 2014).

Among seven non-canonical terminal nucleotidyltransferase family proteins, TUT4 and TUT7 have similar domain organizations (Figure 1), and both are involved in the uridylylation of pre-let-7. Biogenesis of let-7 is regulated by two
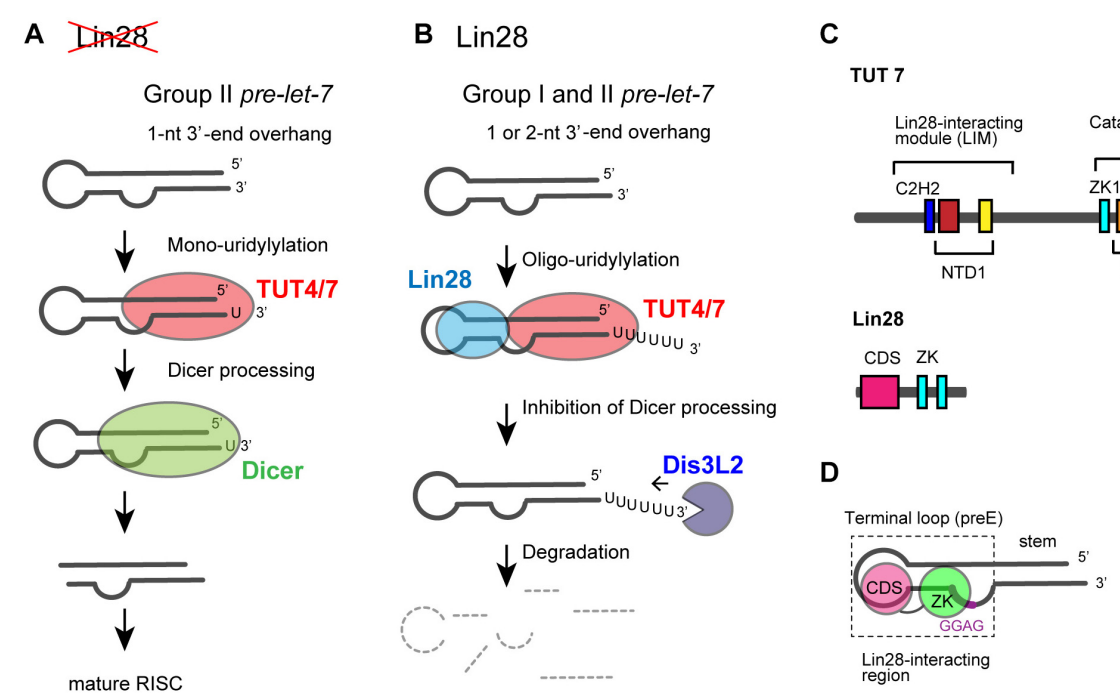

FIGURE 5 | Functional duality of TUT4/7 in the biogenesis of let-7. (A) In the absence of LIN28, mono-uridylylation of pre-let-7 that harbors 1-nt 3'-overhang (group II) by TUT4/7 promotes Dicer processing of pre-let-7. (B) In the presence of LIN28, TUT4/7 oligo-uridylylates pre-let-7 and inhibits Dicer processing of pre-let-7. Oligo-uridylylated pre-let-7 is degraded by DIS3L2, an exonuclease. (C) Schematic representation of domain organization of TUT4/7 and Lin28. ZKs in Lin28 interact with LIM of TUT4/7 in the presence of pre-let-7 (Faehnle et al., 2017; Wang et al., 2017). (D) Schematic representation of the secondary structure of pre-let-7 and interactions with Lin28B (Nam et al., 2011; Wang et al., 2017). ZK of Lin28 binds GGAG motif in pre-let-7 and CDS binds the terminal loop of preE. 
A

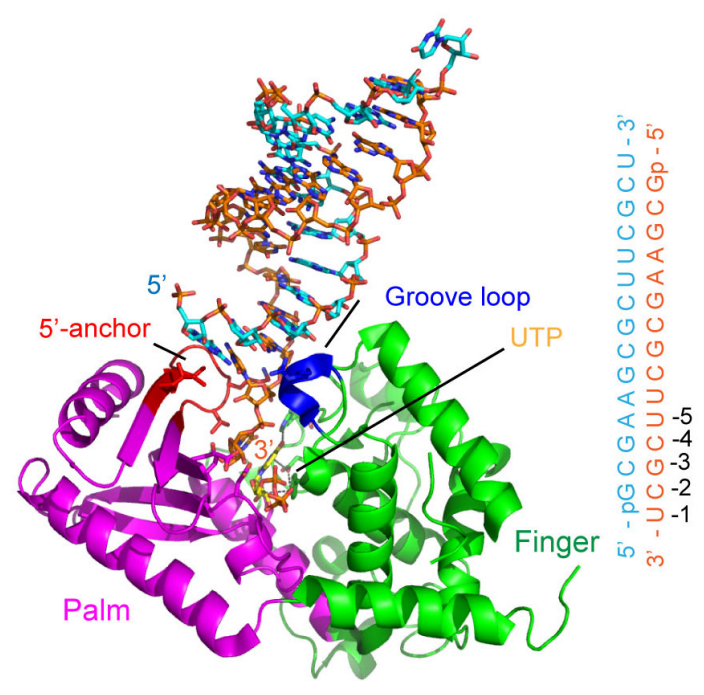

B

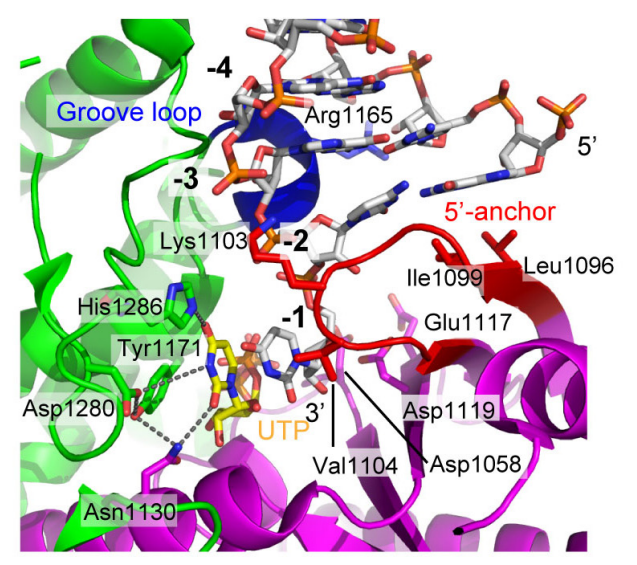

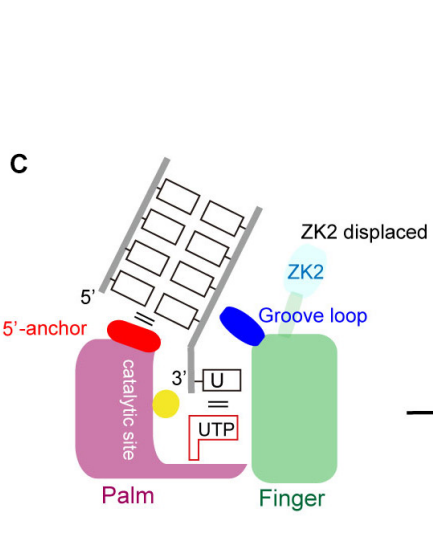

Pre-catalytic stage

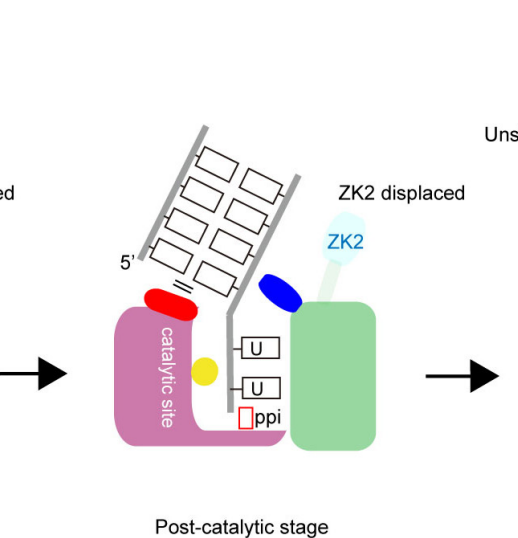

FIGURE 6 | Structure of human TUT7 representing mono-uridylylation. (A) The overall structure of TUT7 CM complexed with dsRNA that mimics the double-helix of group II pre-let-7 and UTP. ZK2 was not visible in the structure suggesting that the ZK2 is displaced. (B) UTP recognition by TUT7. UTP is depicted by sticks.

(C) Schematic representation of mono-uridylylation of pre-let-7 with 1-nt 3'-overhang (group II). After mono-uridylylation of group II pre-let-7 and pyrophosphate (ppi) release, pre-let-7 tanslocates. In the absence of Lin28, the mono-uridylylated pre-let-7 cannot form a stable complex with TUT7, and is easily released from TUT7.

distinct modes of uridylylation of pre-let-7: mono-uridylylation and oligo-uridylylation (Figures 5A,B).

Mono-uridylylation of pre-let-7 is observed in differentiated and somatic cells where Lin28 is not expressed. Group II pre-let-7 with 1-nt $3^{\prime}$-end overhang after Drosha processing is monouridylylated (Heo et al., 2012). This mono-uridylylation of prelet-7 is mediated by TUT4/7, and promotes subsequent Dicer processing, as pre-let-7 with 2-nt $3^{\prime}$-overhang is a good substrate of Dicer. Thus, TUT4/7 promotes biogenesis of let-7, serving as a biogenesis factor (Figure 5A).

On the other hand, in embryonic cells and cancer cells, RNA-binding protein Lin28 is expressed and let-7 expression is repressed. Lin28 binds to a conserved sequence ( $5^{\prime}$-GGAG$\left.3^{\prime}\right)$ in the loop region of pre-let-7after Drosha processing (Heo et al., 2008; Newman et al., 2008; Nam et al., 2011). Lin28 binding to pre-let-7 competes with Dicer cleavage of pre-let-7, recruits TUT4/7, and promotes oligo-uridylylation of pre-let-7 (Heo et al., 2008, 2009; Piskounova et al., 2008;
Hagan et al., 2009; Thornton et al., 2012). Oligo-uridylylation of pre-let-7 inhibits the Dicer processing and causes degradation of pre-let-7 by DIS3L2 (Astuti et al., 2012; Ustianenko et al., 2013), an exonuclease that preferably degrades poly(U) tail. Hence, oligo-uridylylation of pre-let-7 represses expression of mature let-7 (Figure 5B). TUT4 is mainly responsible for the oligo-uridylytation of pre-let-7, because single knockdown of TUT4 is sufficient to increase the mature let-7 levels (Heo et al., 2009; Thornton et al., 2012). On the other hand, TUT7 is thought to have limited or redundant role, because single knockdown of TUT7 has no effect on mature let-7 level, but double knockdown of TUT4 and TUT7 increases mature let-7 more significantly than the single knockdown of TUT4 (Thornton et al., 2012). In the case of Lin28 dependent oligouridylylation, TUT4/7 serves as a negative regulator of let-7 biogenesis, and contributes to tumorigenesis and embryonic stem cell maintenance, by canceling the repression of several genes. 
The functional duality of uridylylation by TUT4/7 depends on the length of $3^{\prime}$-tail of pre-let-7 and the cell type. Lin28 and TUT4/7 act as a molecular switch in the developmental and pathological transition observed in cancer.

\section{Domain Structures of Human TUT4/7 and Lin28}

TUT4 and TUT7 have similar domain organization (Figure 1), and are multi-domain enzymes composed of an N-terminal ZF domain, two nucleotidyltransferase domains (NTD1 and NTD2) connected by a flexible linker, and three zinc knuckle domains (ZK) (CCHC-type zinc fingers in Figure 1). NTD1 in the N-terminal portion of the protein is not an active nucleotidyltransferase, since it lacks three catalytic carboxylates. By contrast, NTD2 has such three catalytic carboxylates and participates in the nucleotidyltransfer reaction (Figure 5C).

During the Lin28-dependent oligo-uridylylation of pre-let-7 by TUT4/7, Lin 28 and pre-let-7 interact with the N-terminal half of TUT4/7 (Nam et al., 2011; Thornton et al., 2012; Faehnle et al., 2017; Wang et al., 2017). The N-terminal and C-terminal halves of TUT4/7 are referred to as LIM and CM, respectively (Figure 5C).

The molecular mechanism of Lin28 binding to pre-let-7 RNA is well understood (Loughlin et al., 2011; Nam et al., 2011; Mayr et al., 2012; Wang et al., 2018). Human Lin28 harbors an N-terminal cold-shock domain, and two C-terminal ZKs. Coldshock domain binds to a stem-loop structure in the pre-element
(preE) and ZKs bind to a conserved GGAG motif located near the $3^{\prime}$-end of preE (Figure 5D). ZKs of Lin28 are necessary and sufficient for the ternary interactions of TUT4/7, Lin28, and pre-let-7 (Faehnle et al., 2017; Wang et al., 2017).

\section{Structure of the Catalytic Core of TUT7 During Mono-Uridylylation}

Recently, crystal structure of a complex of human TUT7 CM with 14-bp palindromic dsRNA and UTP was reported (Faehnle et al., 2017). The RNA used for crystallization contained a 1nt 3 -overhang, thus mimicking the duplex stem of group II pre-let-7 (Heo et al., 2012). Hence, the structure of CM in complex with dsRNA reflects mono-uridylylation of pre-let-7 (Figure 6A).

The overall structure of TUT7 CM shares topological homology with those of yeast Cid1 and vertebrate mitochondrial PAP (Bai et al., 2011; Lunde et al., 2012; Munoz-Tello et al., 2012; Yates et al., 2012; Lapkouski and Hallberg, 2015). It is also homologous to the catalytic core structure of human TUT1 (Yamashita et al., 2017), and consists of palm and finger domains. TUT7 (and TUT4) CM contains ZKs (Figures 1, 5C). However, $\mathrm{ZK} 2$ is not visible in the structure, suggesting that it is displaced. In the structure of CM with dsRNA and UTP, UTP resides at the bottom of the cleft between palm and fingers, as observed in the structure of human TUT1 complexed with UTP. The $\mathrm{O}_{4}$ atom and $\mathrm{O}_{2}$ atom of UTP form hydrogen bonds with His1286 and Asn1130, respectively. The $\mathrm{N}_{3}$ atom of UTP interacts with
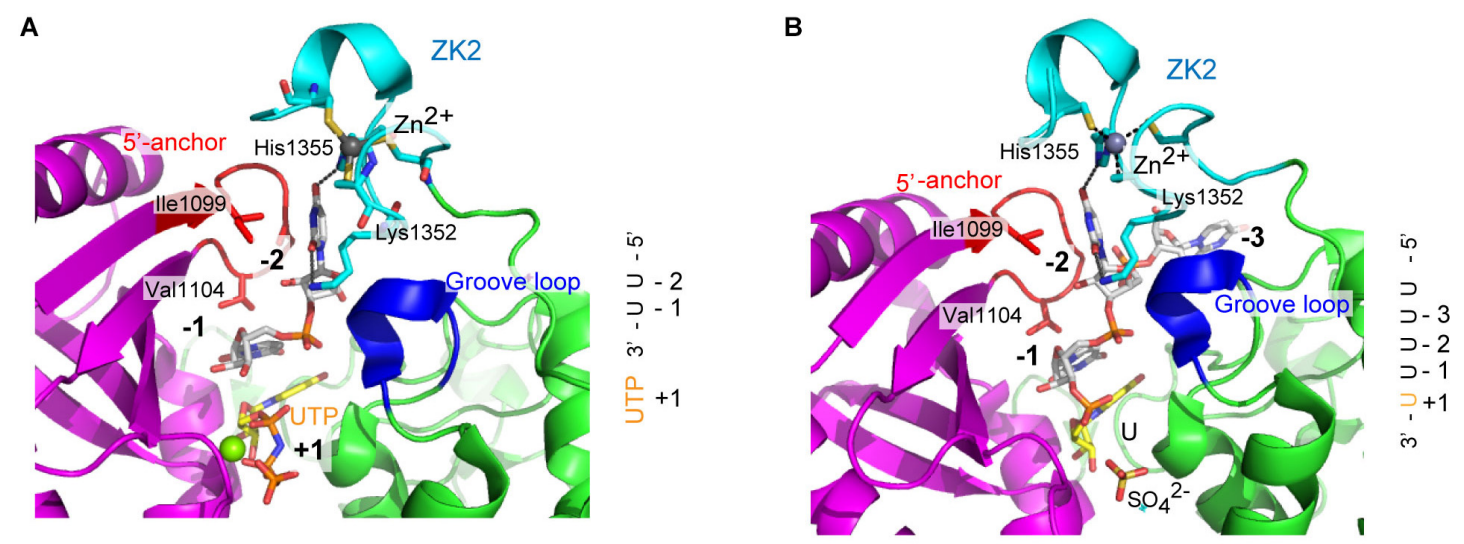

C
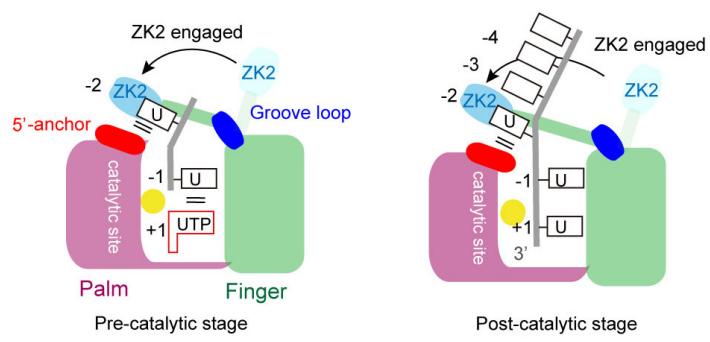

FIGURE 7 | Structure of human TUT7 reflecting oligo-uridylylation. (A) Structure of TUT7 CM complexed with UUOH and UTP, representing the pre-catalytic stage. (B) Structure of TUT7 CM complexed with UUUUUOH (U5), representing the post-catalytic stage. (C) Schematic representation of oligo-uridylylation of pre-let-7 with 2-nt 3'-overhang (group II). ZK2 participates in the recognition of uridine at position -2 to stabilize the $3^{\prime}$-oligo(U) in the pre- (left) and post- (right) catalytic stages. 
Asp1280 via a water molecule (Figure 6B). The mechanism of UTP selection by human TUT7 (and TUT4) is essentially the same as that for yeast Cid1 and human TUT1 (Figure 3D).

The dsRNA, mimicking the duplex stem of pre-let-7, is clamped by two regions: the $5^{\prime}$-anchor and groove loop (Figures 6A,C). Leu1096 and Ile1099 in the $5^{\prime}$-anchor (palm) provide a hydrophobic platform for interactions and stack with the first-base pair of dsRNA. The groove loop (fingers) interacts with the minor groove of dsRNA through van der Waals interactions and hydrogen bonding. Consequently, the $3^{\prime}$-end overhanging nucleotide $\left(3^{\prime}-\mathrm{U}\right)$ of group II pre-miRNA can enter the catalytic pocket. The uracil base of $3^{\prime}-U$ is sandwitched between the uracil base of incoming UTP in the catalytic site and Val1104 in the $5^{\prime}$-anchor. The structure represents the pre-reaction stage of monouridylation. Following the nucleotidyltransfer reaction, the release of byproduct, pyrophosphate, would trigger the translocation of the double helix of pre-let-7, with the double helix of pre-let-7 no longer fixed or stabilized by the $5^{\prime}$-anchor and groove loop. Consequently, TUT7/4 would terminate the mono-uridylylation reaction and release mono-uridylylated pre-let-7 (Figure 6C).

\section{Structure of the Catalytic Core of TUT7 During Oligo-Uridylylation}

Structure of human TUT7 CM complexed with 2-nt oligo(U) $\left(5^{\prime}-\mathrm{UUOH}-3^{\prime}\right)$ and a UTP analog, reflecting oligo-uridylylation (pre-catalytic stage), was reported (Faehnle et al., 2017; Figure 7A). Structure of a TUT7 CM in complex with a 5-nt oligo(U) (5'-UUUUUOH-3'), reflecting post-uridylylation (post-catalytic stage) was also reported (Figure $7 \mathbf{B}$ ). In the
A
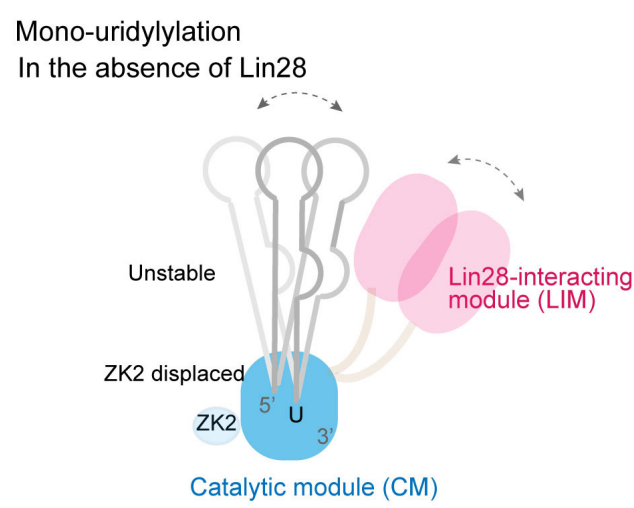

Oligo-uridylylation

In the presence of Lin28

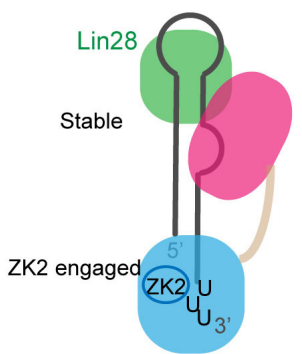

\section{B}

In the absence of Lin28
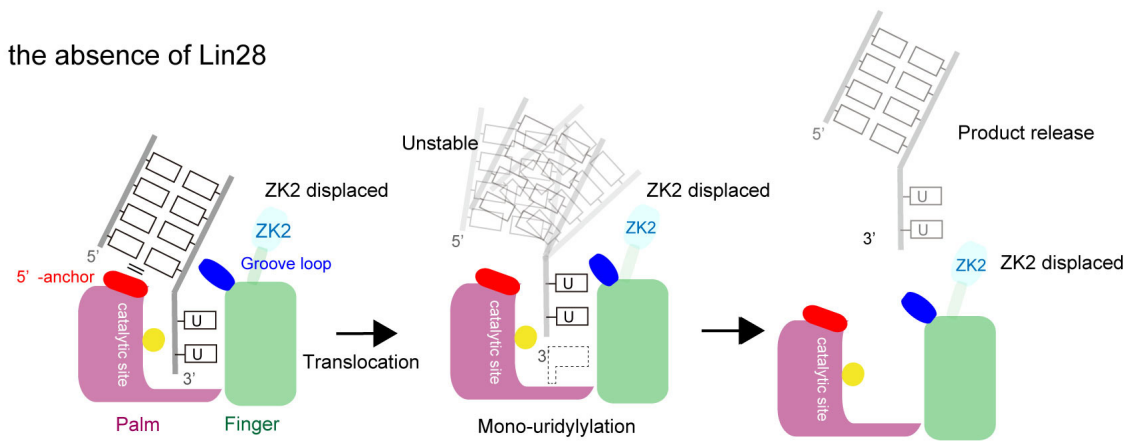

In the presence of Lin28

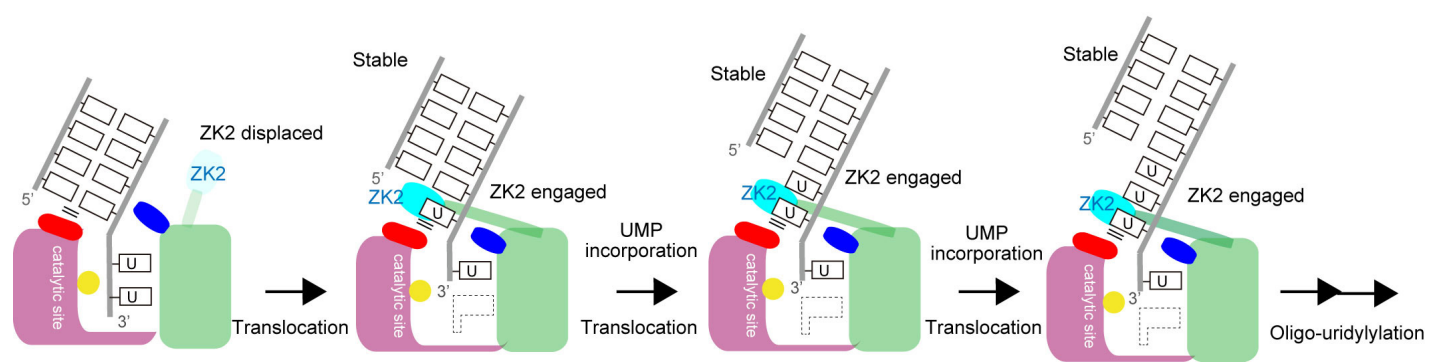

FIGURE 8 | Switching between mono- and oligo-uridylylation. (A) Schematic representation of mono-uridylylation in the absence of Lin28 (left) and oligo-uridylylation in the presence of Lin28 (right). (B) Schematic detailed representations of mono-uridylylation of pre-let-7 in the absence of Lin28 (upper), and oligo-uridylylation of pre-let-7 in the presence of Lin28 (lower). Only the catalytic site in the CM is presented. 
structures of the CM-oligo(U) complex, ZK2 is clearly visible and interacts with the oligo(U) chain. In the structure of the CM-dsRNA complex representing mono-uridylylation, ZK2 is not visible and is displaced because of the presence of dsRNA (Figure 6A).

In both $\mathrm{CM}$-oligo(U) complexes, ZK2 interacts with uridine at a position corresponding to -2 (Figures $7 \mathbf{A}, \mathbf{B}$ ). The $\mathrm{O}_{4}$ atom of uridine at position -2 forms a hydrogen bond with His1355, and the $\mathrm{O}_{2}$ atom of uridine at position -2 forms a hydrogen bond with a water molecule, which also hydrogen-bonds with Lys1353. The uridine at position -1 also hydrogen-bonds with Asn1124, and the uracil base is sandwitched between uracil base at position +1 and Val1104. Thus, ZK2 would stabilize the oligo(U) reaction product and aid the translocation of oligo(U) via uracil-specific interactions at the oligo-uridylylation site (Figure 7C).

\section{Mechanism of Switching Between Mono- and Oligo-Uridylylation}

A TUT7/4 activity switch has been proposed based on the structures of TUT7/4 CM in complex with various RNAs (Figures 8A,B). Transient interaction between TUT7/4 and group II pre-let-7 favors addition and release before oligouridylylation occurs. Hence TUT7/4 mono-uridylylate group II pre-let-7 (Figure 8A). Since group I pre-let-7 with a 2nt $3^{\prime}$-overhang binds at the post-catalytic state, pre-let-7 is released without oligo-uridylylation. The double-stranded stem of pre-let-7 prevents ZK2 engagement in the process.

Lin28 controls the oligo-uridylylation switch by recruiting TUT7/4 LIM to the GGAG motif in the terminal loop of prelet-7 (Figure 8B). The stable ternary complex of TUT7/4, Lin28, and pre-let-7 allows the 3 -end of pre-let-7 to stay in the active site in CM, and supports processive oligo-uridylylation by the CM. During oligo-uridylylation, ZK2 in the CM interacts with $3^{\prime}$-oligo(U) tail and stabilizes the translocation of oligo(U) tail.

It is not yet clear how LIM interacts with ZK of Lin 28 and the GGAG motif of pre-let-7, and how the interaction relocates the $3^{\prime}$-end of pre-let-7 in the catalytic pocket of CM to initiate oligouridylylation. Elucidation of these mechanisms awaits further structural analysis.

\section{REFERENCES}

Achsel, T., Brahms, H., Kastner, B., Bachi, A., Wilm, M., and Luhrmann, R. (1999). A doughnut-shaped heteromer of human Sm-like proteins binds to the 3'-end of U6 snRNA, thereby facilitating U4/U6 duplex formation in vitro. EMBO J. 18, 5789-5802. doi: 10.1093/emboj/18.20.5789

Aphasizhev, R., Suematsu, T., Zhang, L., and Aphasizheva, I. (2016). Constructive edge of uridylation-induced RNA degradation. RNA Biol. 13, 1078-1083. doi: 10.1080/15476286.2016.1229736

Aravind, L., and Koonin, E. V. (1999). DNA polymerase beta-like nucleotidyltransferase superfamily: identification of three new families, classification and evolutionary history. Nucleic Acids Res. 27, 1609-1618. doi: 10.1093/nar/27.7.1609

Astuti, D., Morris, M. R., Cooper, W. N., Staals, R. H., Wake, N. C., Fews, G. A., et al. (2012). Germline mutations in DIS3L2 cause the Perlman syndrome of overgrowth and Wilms tumor susceptibility. Nat. Genet. 44, 277-284. doi: 10.1038/ng.1071

\section{PERSPECTIVES}

TUT1 participates in the target RNA-directed miRNA degradation, TRDM (Haas et al., 2016), where TUT1 oligouridylylates specific miRNAs for degradation by DIS3L2. TUT4 and TUT7 also oligo-uridylylate histone mRNAs for degradation after the inhibition of DNA replication (Schmidt et al., 2011; Lackey et al., 2016). They also oligo-uridylylate Ago cleaved pre-miRNAs with $5^{\prime}$ overhangs (Liu et al., 2014). Similarly, TUT4/7 oligo-uridylylates 3 '-end of polyadenylylated mRNAs and marks them for degradation (Lim et al., 2014; Morgan et al., 2017; Chang et al., 2018). TUT4/7 uridylylates mature miRNAs (Jones et al., 2009; Jones et al., 2012; Thornton et al., 2015), which blocks miRNA activity, probably by affecting either the target specificity or RNA-induced silencing complex loading (Jones et al., 2012). Thus, RNA uridylylation by TUTases plays important roles in various aspects of gene expression. The molecular mechanisms of specific RNA substrates by TUTases remain elusive and cannot be fully explained by the currently solved structures. TUTases would recognize various RNAs either directly or through the regulatory factors which assist TUTases in recognizing specific RNA species. Elucidation of the regulatory mechanism of specific RNA uridylylation by TUTases awaits further study.

\section{AUTHOR CONTRIBUTIONS}

YY and KT wrote the manuscript together.

\section{FUNDING}

Work in the authors' laboratory was supported in part by grants (to KT) from the Funding Program for Next Generation WorldLeading Researchers of JSPS (LS135); by Grants-in-Aid for Scientific Research (A) (18H03980); Grant-in-Aid for Scientific Research on Innovative Areas from JSPS (26113002); Takeda Science Foundation; Japan Foundation for Applied Enzymology; Terumo Foundation for Life Science and Art; and Princess Takamatsu Cancer Research Foundation.

Bai, Y., Srivastava, S. K., Chang, J. H., Manley, J. L., and Tong, L. (2011). Structural basis for dimerization and activity of human PAPD1, a noncanonical poly(A) polymerase. Mol. Cell 41, 311-320. doi: 10.1016/j.molcel.2011.01.013

Balbo, P. B., and Bohm, A. (2007). Mechanism of Poly(A) polymerase: structure of the enzyme-MgATP-RNA ternary complex and kinetic analysis. Structure 15, 1117-1131. doi: 10.1016/j.str.2007.07.010

Bard, J., Zhelkovsky, A. M., Helmling, S., Earnest, T. N., Moore, C. L., and Bohm, A. (2000). Structure of yeast poly(A) polymerase alone and in complex with 3'-dATP. Science 289, 1346-1349. doi: 10.1126/science.289.5483. 1346

Beelman, C. A., and Parker, R. (1995). Degradation of mRNA in eukaryotes. Cell 81, 179-183. doi: 10.1016/0092-8674(95)90326-7

Bell, M., Schreiner, S., Damianov, A., Reddy, R., and Bindereif, A. (2002). p110, a novel human $\mathrm{U} 6$ snRNP protein and U4/U6 snRNP recycling factor. EMBO J. 21, 2724-2735. doi: 10.1093/emboj/21.11.2724

Berndt, H., Harnisch, C., Rammelt, C., Stohr, N., Zirkel, A., Dohm, J. C., et al. (2012). Maturation of mammalian H/ACA box snoRNAs: PAPD5-dependent 
adenylation and PARN-dependent trimming. RNA 18, 958-972. doi: 10.1261/ rna.032292.112

Betat, H., and Morl, M. (2015). The CCA-adding enzyme: a central scrutinizer in tRNA quality control. Bioessays 37, 975-982. doi: 10.1002/bies.201500043

Bortolamiol-Becet, D., Hu, F. Q., Jee, D., Wen, J. Y., Okamura, K., Lin, C. J., et al. (2015). Selective suppression of the splicing-mediated microrna pathway by the terminal uridyltransferase tailor. Mol. Cell 59, 217-228. doi: 10.1016/j.molcel. 2015.05.034

Braun, J. E., Huntzinger, E., and Izaurralde, E. (2012). A molecular link between miRISCs and deadenylases provides new insight into the mechanism of gene silencing by microRNAs. Cold Spring Harb. Perspect. Biol. 4:a012328. doi: 10. 1101/cshperspect.a012328

Bussing, I., Slack, F. J., and Grosshans, H. (2008). let-7 microRNAs in development, stem cells and cancer. Trends Mol. Med. 14, 400-409. doi: 10.1016/j.molmed. 2008.07.001

Carpousis, A. J., Vanzo, N. F., and Raynal, L. C. (1999). mRNA degradation: a tale of poly(A) and multiprotein machines. Trends Genet. 15, 24-28. doi: 10.1016/ S0168-9525(98)01627-8

Chang, H., Yeo, J., Kim, J. G., Kim, H., Lim, J., Lee, M., et al. (2018). Terminal uridylyltransferases execute programmed clearance of maternal transcriptome in vertebrate embryos. Mol. Cell 70, 78.e7-82.e7. doi: 10.1016/j.molcel.2018.03. 004

D'Ambrogio, A., Gu, W., Udagawa, T., Mello, C. C., and Richter, J. D. (2012). Specific miRNA stabilization by Gld2-catalyzed monoadenylation. Cell Rep. 2, 1537-1545. doi: 10.1016/j.celrep.2012.10.023

De Almeida, C., Scheer, H., Zuber, H., and Gagliardi, D. (2018). RNA uridylation: a key posttranscriptional modification shaping the coding and noncoding transcriptome. Wiley Interdiscip. Rev. RNA 9. doi: 10.1002/wrna.1440

Deutscher, M. P. (1990). Transfer RNA nucleotidyltransferase. Methods Enzymol. 181, 434-439. doi: 10.1016/0076-6879(90)81141-G

Dreyfus, M., and Régnier, P. (2002). The Poly(A) tail of mRNAs: bodyguard in eukaryotes, scavenger in bacteria. Cell 111, 611-613. doi: 10.1016/S00928674(02)01137-6

Edmonds, M. (2002). A history of poly A sequences: from formation to factors to function. Prog. Nucleic Acid Res. Mol. Biol. 71, 285-389. doi: 10.1016/S00796603(02)71046-5

Faehnle, C. R., Walleshauser, J., and Joshua-Tor, L. (2017). Multi-domain utilization by TUT4 and TUT7 in control of let-7 biogenesis. Nat. Struct. Mol. Biol. 24, 658-665. doi: 10.1038/nsmb.3428

Fica, S. M., Tuttle, N., Novak, T., Li, N. S., Lu, J., Koodathingal, P., et al. (2013). RNA catalyses nuclear pre-mRNA splicing. Nature 503, 229-234. doi: 10.1038/ nature12734

Glahder, J. A., and Norrild, B. (2011). Involvement of hGLD-2 in cytoplasmic polyadenylation of human p53 mRNA. APMIS 119, 769-775. doi: 10.1111/j. 1600-0463.2011.02804.x

Gonzales, M. L., Mellman, D. L., and Anderson, R. A. (2008). CKIalpha is associated with and phosphorylates star-PAP and is also required for expression of select star-PAP target messenger RNAs. J. Biol. Chem. 283, 12665-12673. doi: 10.1074/jbc.M800656200

Green, R., and Noller, H. F. (1997). Ribosomes and translation. Annu. Rev. Biochem. 66, 679-716. doi: 10.1146/annurev.biochem.66.1.679

Ha, M., and Kim, V. N. (2014). Regulation of microRNA biogenesis. Nat. Rev. Mol. Cell Biol. 15, 509-524. doi: 10.1038/nrm3838

Hagan, J. P., Piskounova, E., and Gregory, R. I. (2009). Lin28 recruits the TUTase Zcchc11 to inhibit let-7 maturation in mouse embryonic stem cells. Nat. Struct. Mol. Biol. 16, 1021-1025. doi: 10.1038/nsmb.1676

Haas, G., Cetin, S., Messmer, M., Chane-Woon-Ming, B., Terenzi, O., Chicher, J., et al. (2016). Identification of factors involved in target RNA-directed microRNA degradation. Nucleic Acids Res. 44, 2873-2887. doi: 10.1093/nar/ gkw040

Heo, I., Ha, M., Lim, J., Yoon, M. J., Park, J. E., Kwon, S. C., et al. (2012). Monouridylation of pre-microRNA as a key step in the biogenesis of group II let-7 microRNAs. Cell 151, 521-532. doi: 10.1016/j.cell.2012.09.022

Heo, I., Joo, C., Cho, J., Ha, M., Han, J., and Kim, V. N. (2008). Lin28 mediates the terminal uridylation of let-7 precursor MicroRNA. Mol. Cell 32, 276-284. doi: 10.1016/j.molcel.2008.09.014

Heo, I., Joo, C., Kim, Y. K., Ha, M., Yoon, M. J., Cho, J., et al. (2009). TUT4 in concert with Lin28 suppresses microRNA biogenesis through
pre-microRNA uridylation. Cell 138, 696-708. doi: 10.1016/j.cell.2009 08.002

Hilcenko, C., Simpson, P. J., Finch, A. J., Bowler, F. R., Churcher, M. J., Jin, L., et al. (2013). Aberrant 3' oligoadenylation of spliceosomal U6 small nuclear RNA in poikiloderma with neutropenia. Blood 121, 1028-1038. doi: 10.1182/ blood-2012-10-461491

Houbaviy, H. B., Murray, M. F., and Sharp, P. A. (2003). Embryonic stem cell-specific microRNAs. Dev. Cell 5, 351-358. doi: 10.1016/S1534-5807(03) 00227-2

Jandrositz, A., and Guthrie, C. (1995). Evidence for a Prp24 binding site in U6 snRNA and in a putative intermediate in the annealing of U6 and U4 snRNAs. EMBO J. 14, 820-832. doi: 10.1002/j.1460-2075.1995.tb07060.x

Johnson, S. M., Grosshans, H., Shingara, J., Byrom, M., Jarvis, R., Cheng, A., et al. (2005). RAS is regulated by the let-7 microRNA family. Cell 120, 635-647. doi: 10.1016/j.cell.2005.01.014

Jones, M. R., Blahna, M. T., Kozlowski, E., Matsuura, K. Y., Ferrari, J. D., Morris, S. A., et al. (2012). Zcchc11 uridylates mature miRNAs to enhance neonatal IGF-1 expression, growth, and survival. PLoS Genet. 8:e1003105. doi: 10.1371/ journal.pgen. 1003105

Jones, M. R., Quinton, L. J., Blahna, M. T., Neilson, J. R., Fu, S., Ivanov, A. R., et al. (2009). Zcchcl1-dependent uridylation of microRNA directs cytokine expression. Nat. Cell Biol. 11, 1157-1163. doi: 10.1038/ncb1931

Karaduman, R., Fabrizio, P., Hartmuth, K., Urlaub, H., and Luhrmann, R. (2006). RNA structure and RNA-protein interactions in purified yeast U6 snRNPs. J. Mol. Biol. 356, 1248-1262. doi: 10.1016/j.jmb.2005.12.013

Katoh, T., Sakaguchi, Y., Miyauchi, K., Suzuki, T., Kashiwabara, S., Baba, T., et al. (2009). Selective stabilization of mammalian microRNAs by 3 ' adenylation mediated by the cytoplasmic poly(A) polymerase GLD-2. Genes Dev. 23, 433438. doi: 10.1101/gad.1761509

Kenan, D. J., Query, C. C., and Keene, J. D. (1991). RNA recognition: towards identifying determinants of specificity. Trends Biochem. Sci. 16, 214-220. doi: 10.1016/0968-0004(91)90088-D

Kim, D. F., and Green, R. (1999). Base-pairing between $23 \mathrm{~S}$ rRNA and tRNA in the ribosomal A site. Mol. Cell 4, 859-864. doi: 10.1016/S1097-2765(00)80395-0

Kuhn, C. D., Wilusz, J. E., Zheng, Y., Beal, P. A., and Joshua-Tor, L. (2015). On-enzyme refolding permits small RNA and tRNA surveillance by the CCA-adding enzyme. Cell 160, 644-658. doi: 10.1016/j.cell.2015. 01.005

Kwak, J. E., Wang, L., Ballantyne, S., Kimble, J., and Wickens, M. (2004). Mammalian GLD-2 homologs are poly(A) polymerases. Proc. Natl. Acad. Sci. U.S.A. 101, 4407-4412. doi: 10.1073/pnas.0400779101

Kwak, J. E., and Wickens, M. (2007). A family of poly(U) polymerases. RNA 13, 860-867. doi: 10.1261/rna.514007

Lackey, P. E., Welch, J. D., and Marzluff, W. F. (2016). TUT7 catalyzes the uridylation of the 3' end for rapid degradation of histone mRNA. RNA 22, 1673-1688. doi: 10.1261/rna.058107.116

Laishram, R. S., and Anderson, R. A. (2010). The poly A polymerase StarPAP controls 3 '-end cleavage by promoting CPSF interaction and specificity toward the pre-mRNA. EMBO J. 29, 4132-4145. doi: 10.1038/emboj. 2010.287

Laishram, R. S., Barlow, C. A., and Anderson, R. A. (2011). CKI isoforms alpha and epsilon regulate Star-PAP target messages by controlling Star-PAP poly(A) polymerase activity and phosphoinositide stimulation. Nucleic Acids Res. 39, 7961-7973. doi: 10.1093/nar/gkr549

Lapkouski, M., and Hallberg, B. M. (2015). Structure of mitochondrial poly(A) RNA polymerase reveals the structural basis for dimerization, ATP selectivity and the SPAX4 disease phenotype. Nucleic Acids Res. 43, 9065-9075. doi: 10. 1093/nar/gkv861

Le Pen, J., Jiang, H., Di Domenico, T., Kneuss, E., Kosalka, J., Leung, C., et al. (2018). Terminal uridylyltransferases target RNA viruses as part of the innate immune system. Nat. Struct. Mol. Biol. 25, 778-786. doi: 10.1038/s41594-0180106-9

Lee, M., Kim, B., and Kim, V. N. (2014). Emerging roles of RNA modification: m(6)A and U-tail. Cell 158, 980-987. doi: 10.1016/j.cell.2014.08.005

Li, F., Xiong, Y., Wang, J., Cho, H. D., Tomita, K., Weiner, A. M., et al. (2002). Crystal structures of the Bacillus stearothermophilus CCA-adding enzyme and its complexes with ATP or CTP. Cell 111, 815-824. doi: 10.1016/S00928674(02)01115-7 
Lim, J., Ha, M., Chang, H., Kwon, S. C., Simanshu, D. K., Patel, D. J., et al. (2014). Uridylation by TUT4 and TUT7 marks mRNA for degradation. Cell 159, 1365-1376. doi: 10.1016/j.cell.2014.10.055

Lim, J., Kim, D., Lee, Y. S., Ha, M., Lee, M., Yeo, J., et al. (2018). Mixed tailing by TENT4A and TENT4B shields mRNA from rapid deadenylation. Science 361, 701-704. doi: 10.1126/science.aam5794

Liu, X., Zheng, Q., Vrettos, N., Maragkakis, M., Alexiou, P., Gregory, B. D., et al. (2014). A MicroRNA precursor surveillance system in quality control of MicroRNA synthesis. Mol. Cell 55, 868-879. doi: 10.1016/j.molcel.2014.07.017

Loughlin, F. E., Gebert, L. F., Towbin, H., Brunschweiger, A., Hall, J., and Allain, F. H. (2011). Structural basis of pre-let-7 miRNA recognition by the zinc knuckles of pluripotency factor Lin28. Nat. Struct. Mol. Biol. 19, 84-89. doi: 10.1038/nsmb.2202

Lunde, B. M., Magler, I., and Meinhart, A. (2012). Crystal structures of the Cid1 poly (U) polymerase reveal the mechanism for UTP selectivity. Nucleic Acids Res. 40, 9815-9824. doi: 10.1093/nar/gks740

Martin, G., and Keller, W. (2007). RNA-specific ribonucleotidyl transferases. RNA 13, 1834-1849. doi: 10.1261/rna.652807

Martin, G., Keller, W., and Doublie, S. (2000). Crystal structure of mammalian poly(A) polymerase in complex with an analog of ATP. EMBO J. 19, 4193-4203. doi: $10.1093 / \mathrm{emboj} / 19.16 .4193$

Mayr, F., Schutz, A., Doge, N., and Heinemann, U. (2012). The Lin28 cold-shock domain remodels pre-let-7 microRNA. Nucleic Acids Res. 40, 7492-7506. doi: 10.1093/nar/gks355

Mellman, D. L., Gonzales, M. L., Song, C., Barlow, C. A., Wang, P., Kendziorski, C., et al. (2008). A PtdIns4,5P2-regulated nuclear poly(A) polymerase controls expression of select mRNAs. Nature 451, 1013-1017. doi: 10.1038/nature06666

Menezes, M. R., Balzeau, J., and Hagan, J. P. (2018). 3' RNA uridylation in epitranscriptomics, gene regulation, and disease. Front. Mol. Biosci. 5:61. doi: 10.3389/fmolb.2018.00061

Mohan, N., Sudheesh, A. P., Francis, N., Anderson, R., and Laishram, R. S. (2015). Phosphorylation regulates the Star-PAP-PIPKIalpha interaction and directs specificity toward mRNA targets. Nucleic Acids Res. 43, 7005-7020. doi: 10.1093/nar/gkv676

Moore, M. J., and Proudfoot, N. J. (2009). Pre-mRNA processing reaches back to transcription and ahead to translation. Cell 136, 688-700. doi: 10.1016/j.cell. 2009.02.001

Moravcevic, K., Mendrola, J. M., Schmitz, K. R., Wang, Y. H., Slochower, D., Janmey, P. A., et al. (2010). Kinase associated-1 domains drive MARK/PAR1 kinases to membrane targets by binding acidic phospholipids. Cell 143, 966977. doi: 10.1016/j.cell.2010.11.028

Morgan, M., Much, C., DiGiacomo, M., Azzi, C., Ivanova, I., Vitsios, D. M., et al. (2017). mRNA 3' uridylation and poly(A) tail length sculpt the mammalian maternal transcriptome. Nature 548, 347-351. doi: 10.1038/nature23318

Mroczek, S., Krwawicz, J., Kutner, J., Lazniewski, M., Kucinski, I., Ginalski, K., et al. (2012). C16orf57, a gene mutated in poikiloderma with neutropenia, encodes a putative phosphodiesterase responsible for the U6 snRNA 3' end modification. Genes Dev. 26, 1911-1925. doi: 10.1101/gad.193169.112

Mullen, T. E., and Marzluff, W. F. (2008). Degradation of histone mRNA requires oligouridylation followed by decapping and simultaneous degradation of the mRNA both 5' to 3' and 3' to 5'. Genes Dev. 22, 50-65. doi: 10.1101/gad.1622708

Munoz-Tello, P., Gabus, C., and Thore, S. (2012). Functional implications from the Cid1 poly(U) polymerase crystal structure. Structure 20, 977-986. doi: 10.1016/ j.str.2012.04.006

Munoz-Tello, P., Gabus, C., and Thore, S. (2014). A critical switch in the enzymatic properties of the Cid1 protein deciphered from its productbound crystal structure. Nucleic Acids Res. 42, 3372-3380. doi: 10.1093/nar/ gkt1278

Nagaike, T., Suzuki, T., Katoh, T., and Ueda, T. (2005). Human mitochondrial mRNAs are stabilized with polyadenylation regulated by mitochondria-specific poly(A) polymerase and polynucleotide phosphorylase. J. Biol. Chem. 280, 19721-19727. doi: 10.1074/jbc.M500804200

Nam, Y., Chen, C., Gregory, R. I., Chou, J. J., and Sliz, P. (2011). Molecular basis for interaction of let-7 microRNAs with Lin28. Cell 147, 1080-1091. doi: $10.1016 /$ j.cell.2011.10.020

Newman, M. A., Thomson, J. M., and Hammond, S. M. (2008). Lin-28 interaction with the Let-7 precursor loop mediates regulated microRNA processing. RNA 14, 1539-1549. doi: 10.1261/rna.1155108
Nissen, P., Hansen, J., Ban, N., Moore, P. B., and Steitz, T. A. (2000). The structural basis of ribosome activity in peptide bond synthesis. Science 289, 920-930. doi: 10.1126/science.289.5481.920

Norbury, C. J. (2010). 3' Uridylation and the regulation of RNA function in the cytoplasm. Biochem. Soc. Trans. 38, 1150-1153. doi: 10.1042/bst0381150

Ogami, K., Cho, R., and Hoshino, S. (2013). Molecular cloning and characterization of a novel isoform of the non-canonical poly(A) polymerase PAPD7. Biochem. Biophys. Res. Commun. 432, 135-140. doi: 10.1016/j.bbrc.2013.01.072

Okabe, M., Tomita, K., Ishitani, R., Ishii, R., Takeuchi, N., Arisaka, F., et al. (2003). Divergent evolutions of trinucleotide polymerization revealed by an archaeal CCA-adding enzyme structure. EMBO J. 22, 5918-5927. doi: 10.1093/emboj/ cdg563

Pan, B., Xiong, Y., and Steitz, T. A. (2010). How the CCA-adding enzyme selects adenine over cytosine at position 76 of tRNA. Science 330, 937-940. doi: 10. 1126/science.1194985

Piskounova, E., Viswanathan, S. R., Janas, M., LaPierre, R. J., Daley, G. Q., Sliz, P., et al. (2008). Determinants of microRNA processing inhibition by the developmentally regulated RNA-binding protein Lin28. J. Biol. Chem. 283, 21310-21314. doi: 10.1074/jbc.C800108200

Régnier, P., and Hajnsdorf, E. (2009). Poly(A)-Assisted RNA decay and modulators of RNA stability. Prog. Mol. Biol. Transl. Sci. 85, 137-185. doi: 10.1016/S00796603(08)00804-0

Raghunathan, P. L., and Guthrie, C. (1998). A spliceosomal recycling factor that reanneals U4 and U6 small nuclear ribonucleoprotein particles. Science 279, 857-860. doi: 10.1126/science.279.5352.857

Reimao-Pinto, M. M., Ignatova, V., Burkard, T. R., Hung, J. H., Manzenreither, R. A., Sowemimo, I., et al. (2015). Uridylation of RNA hairpins by tailor confines the emergence of MicroRNAs in Drosophila. Mol. Cell 59, 203-216. doi: 10.1016/j.molcel.2015.05.033

Reinhart, B. J., Slack, F. J., Basson, M., Pasquinelli, A. E., Bettinger, J. C., Rougvie, A. E., et al. (2000). The 21-nucleotide let-7 RNA regulates developmental timing in Caenorhabditis elegans. Nature 403, 901-906. doi: 10.1038/35002607

Rinke, J., and Steitz, J. A. (1985). Association of the lupus antigen La with a subset of U6 snRNA molecules. Nucleic Acids Res. 13, 2617-2629. doi: 10.1093/nar/13. 7.2617

Rissland, O. S. (2015). Tailoring MicroRNA function: the role of uridylation in antagonizing mirtron expression. Mol. Cell 59, 141-143. doi: 10.1016/j.molcel. 2015.07.001

Rissland, O. S., Mikulasova, A., and Norbury, C. J. (2007). Efficient RNA polyuridylation by noncanonical poly(A) polymerases. Mol. Cell. Biol. 27, 3612-3624. doi: 10.1128/MCB.02209-06

Sachs, A. B., Sarnow, P., and Hentze, M. W. (1997). Starting at the beginning, middle, and end: translation initiation in eukaryotes. Cell 89, 831-838. doi: 10.1016/S0092-8674(00)80268-8

Schmidt, M. J., West, S., and Norbury, C. J. (2011). The human cytoplasmic RNA terminal U-transferase ZCCHC11 targets histone mRNAs for degradation. RNA 17, 39-44. doi: 10.1261/rna.2252511

Scott, D. D., and Norbury, C. J. (2013). RNA decay via 3' uridylation. Biochim. Biophys. Acta 1829, 654-665. doi: 10.1016/j.bbagrm.2013.01.009

Shchepachev, V., Wischnewski, H., Missiaglia, E., Soneson, C., and Azzalin, C. M. (2012). Mpn1, mutated in poikiloderma with neutropenia protein 1, is a conserved 3'-to-5' RNA exonuclease processing U6 small nuclear RNA. Cell Rep. 2, 855-865. doi: 10.1016/j.celrep.2012.08.031

Sprinzl, M., and Cramer, F. (1979). The -C-C-A end of tRNA and its role in protein biosynthesis. Prog Nucleic Acid Res. Mol. Biol. 22, 1-69. doi: 10.1016/S00796603(08)60798-9

Stevenson, A. L., and Norbury, C. J. (2006). The Cid1 family of non-canonical poly(A) polymerases. Yeast 23, 991-1000. doi: 10.1002/yea.1408

Sudo, H., Nozaki, A., Uno, H., Ishida, Y., and Nagahama, M. (2016). Interaction properties of human TRAMP-like proteins and their role in prerRNA 5'ETS turnover. FEBS Lett. 590, 2963-2972. doi: 10.1002/1873-3468. 12314

Takamizawa, J., Konishi, H., Yanagisawa, K., Tomida, S., Osada, H., Endoh, H., et al. (2004). Reduced expression of the let-7 microRNAs in human lung cancers in association with shortened postoperative survival. Cancer Res. 64, 3753-3756. doi: 10.1158/0008-5472.CAN-04-0637

Thornton, J. E., Chang, H. M., Piskounova, E., and Gregory, R. I. (2012). Lin28mediated control of let-7 microRNA expression by alternative TUTases Zcchc11 
(TUT4) and Zcchc6 (TUT7). RNA 18, 1875-1885. doi: 10.1261/rna.0345 38.112

Thornton, J. E., Du, P., Jing, L., Sjekloca, L., Lin, S., Grossi, E., et al. (2015). Selective microRNA uridylation by Zcchc6 (TUT7) and Zcchc11 (TUT4). Nucleic Acids Res. 42, 11777-11791. doi: 10.1093/nar/gku805

Thornton, J. E., and Gregory, R. I. (2012). How does Lin28 let-7 control development and disease? Trends Cell Biol. 22, 474-482. doi: 10.1016/j.tcb.2012. 06.001

Toh, Y., Numata, T., Watanabe, K., Takeshita, D., Nureki, O., and Tomita, K. (2008). Molecular basis for maintenance of fidelity during the CCA-adding reaction by a CCA-adding enzyme. EMBO J. 27, 1944-1952. doi: 10.1038/ emboj.2008.124

Toh, Y., Takeshita, D., Nagaike, T., Numata, T., and Tomita, K. (2011). Mechanism for the alteration of the substrate specificities of template-independent RNA polymerases. Structure 19, 232-243. doi: 10.1016/j.str.2010.12.006

Toh, Y., Takeshita, D., Numata, T., Fukai, S., Nureki, O., and Tomita, K. (2009). Mechanism for the definition of elongation and termination by the class II CCA-adding enzyme. EMBO J. 28, 3353-3365. doi: 10.1038/emboj. 2009.260

Tomecki, R., Dmochowska, A., Gewartowski, K., Dziembowski, A., and Stepien, P. P. (2004). Identification of a novel human nuclear-encoded mitochondrial poly(A) polymerase. Nucleic Acids Res. 32, 6001-6014. doi: 10.1093/nar/gkh923

Tomita, K., Fukai, S., Ishitani, R., Ueda, T., Takeuchi, N., Vassylyev, D. G., et al. (2004). Structural basis for template-independent RNA polymerization. Nature 430, 700-704. doi: 10.1038/nature02712

Tomita, K., Ishitani, R., Fukai, S., and Nureki, O. (2006). Complete crystallographic analysis of the dynamics of CCA sequence addition. Nature 443, 956-960. doi: 10.1038/nature05204

Tomita, K., and Weiner, A. M. (2001). Collaboration between CC- and A-adding enzymes to build and repair the 3'-terminal CCA of tRNA in Aquifex aeolicus. Science 294, 1334-1336. doi: 10.1126/science.1063816

Tomita, K., and Weiner, A. M. (2002). Closely related CC- and A-adding enzymes collaborate to construct and repair the 3'-terminal CCA of tRNA in Synechocystis sp. and Deinococcus radiodurans. J. Biol. Chem. 277, 48192-48198. doi: 10.1074/jbc.M207527200

Tomita, K., and Yamashita, S. (2014). Molecular mechanisms of templateindependent RNA polymerization by tRNA nucleotidyltransferases. Front. Genet. 5:36. doi: 10.3389/fgene.2014.00036

Trippe, R., Guschina, E., Hossbach, M., Urlaub, H., Luhrmann, R., and Benecke, B. J. (2006). Identification, cloning, and functional analysis of the human U6 snRNA-specific terminal uridylyl transferase. RNA 12, 1494-1504. doi: 10.1261/ rna.87706

Trippe, R., Richly, H., and Benecke, B. J. (2003). Biochemical characterization of a U6 small nuclear RNA-specific terminal uridylyltransferase. Eur. J. Biochem. 270, 971-980. doi: 10.1046/j.1432-1033.2003.03466.x

Trippe, R., Sandrock, B., and Benecke, B. J. (1998). A highly specific terminal uridylyl transferase modifies the 3'-end of U6 small nuclear RNA. Nucleic Acids Res. 26, 3119-3126. doi: 10.1093/nar/26.13.3119

Tsang, W. P., and Kwok, T. T. (2008). Let-7a microRNA suppresses therapeuticsinduced cancer cell death by targeting caspase-3. Apoptosis 13, 1215-1222. doi: 10.1007/s10495-008-0256-Z

Ustianenko, D., Hrossova, D., Potesil, D., Chalupnikova, K., Hrazdilova, K., Pachernik, J., et al. (2013). Mammalian DIS3L2 exoribonuclease targets the uridylated precursors of let-7 miRNAs. RNA 19, 1632-1638. doi: 10.1261/rna. 040055.113

Vidal, V. P., Verdone, L., Mayes, A. E., and Beggs, J. D. (1999). Characterization of U6 snRNA-protein interactions. RNA 5, 1470-1481. doi: 10.1017/ S1355838299991355

Wahle, E., and Rüegsegger, U. (1999). 3'-End processing of pre-mRNA in eukaryotes. FEMS Microbiol. Rev. 23, 277-295. doi: 10.1016/S0168-6445(99) 00008-X

Walter, N. G., Yang, N., and Burke, J. M. (2000). Probing non-selective cation binding in the hairpin ribozyme with Tb(III). J. Mol. Biol. 298, 539-555. doi: 10.1006/jmbi.2000.3691

Wang, L., Nam, Y., Lee, A. K., Yu, C., Roth, K., Chen, C., et al. (2017). LIN28 zinc knuckle domain is required and sufficient to induce let-7 oligouridylation. Cell Rep. 18, 2664-2675. doi: 10.1016/j.celrep.2017.02.044

Wang, L., Rowe, R. G., Jaimes, A., Yu, C., Nam, Y., Pearson, D. S., et al. (2018). Small-molecule inhibitors disrupt let-7 oligouridylation and release the selective blockade of let-7 processing by LIN28. Cell Rep. 23, 3091-3101. doi: 10.1016/j.celrep.2018.04.116

Wang, S. W., Toda, T., MacCallum, R., Harris, A. L., and Norbury, C. (2000). Cid1, a fission yeast protein required for S-M checkpoint control when DNA polymerase delta or epsilon is inactivated. Mol. Cell. Biol. 20, 3234-3244. doi: 10.1128/MCB.20.9.3234-3244.2000

Warkocki, Z., Krawczyk, P. S., Adamska, D., Bijata, K., Garcia-Perez, J. L., and Dziembowski, A. (2018). Uridylation by TUT4/7 restricts retrotransposition of human LINE-1s. Cell 174, 1537.e1529-1548.e1529. doi: 10.1016/j.cell.2018.07. 022

Weiner, A. M. (2004). tRNA maturation: RNA polymerization without a nucleic acid template. Curr. Biol. 14, R883-R885. doi: 10.1016/j.cub.2004.09.069

Wickens, M., and Kwak, J. E. (2008). A tail tale for U. Science 319, 1344-1345. doi: $10.1126 /$ science. 1154946

Will, C. L., and Luhrmann, R. (2011). Spliceosome structure and function. Cold Spring Harb. Perspect. Biol. 3:a003707. doi: 10.1101/cshperspect.a003707

Wilusz, C. J., and Wilusz, J. (2008). New ways to meet your (3') end oligouridylation as a step on the path to destruction. Genes Dev. 22, 1-7. doi: 10.1101/gad. 1634508

Wilusz, C. J., and Wilusz, J. (2013). Lsm proteins and Hfq: life at the 3' end. RNA Biol. 10, 592-601. doi: 10.4161/rna.23695

Wilusz, J. E., Whipple, J. M., Phizicky, E. M., and Sharp, P. A. (2011). tRNAs marked with CCACCA are targeted for degradation. Science 334, 817-821. doi: $10.1126 /$ science. 1213671

Xiong, Y., Li, F., Wang, J., Weiner, A. M., and Steitz, T. A. (2003). Crystal structures of an archaeal class I CCA-adding enzyme and its nucleotide complexes. Mol. Cell 12, 1165-1172. doi: 10.1016/S1097-2765(03)00440-4

Xiong, Y., and Steitz, T. A. (2004). Mechanism of transfer RNA maturation by CCA-adding enzyme without using an oligonucleotide template. Nature 430, 640-645. doi: 10.1038/nature02711

Xiong, Y., and Steitz, T. A. (2006). A story with a good ending: tRNA 3'-end maturation by CCA-adding enzymes. Curr. Opin. Struct. Biol. 16, 12-17. doi: 10.1016/j.sbi.2005.12.001

Yamashita, S., Martinez, A., and Tomita, K. (2015). Measurement of acceptorTPsiC helix length of tRNA for TERMINAL A76-addition by A-adding enzyme. Structure 23, 830-842. doi: 10.1016/j.str.2015.03.013

Yamashita, S., Takagi, Y., Nagaike, T., and Tomita, K. (2017). Crystal structures of U6 snRNA-specific terminal uridylyltransferase. Nat. Commun. 8:15788. doi: $10.1038 /$ ncomms 15788

Yamashita, S., Takeshita, D., and Tomita, K. (2014). Translocation and rotation of tRNA during template-independent RNA polymerization by tRNA nucleotidyltransferase. Structure 22, 315-325. doi: 10.1016/j.str.2013.12.002

Yamashita, S., and Tomita, K. (2016). Mechanism of 3'-matured tRNA discrimination from 3'-immature tRNA by Class-II CCA-adding enzyme. Structure 24, 918-925. doi: 10.1016/j.str.2016.03.022

Yates, L. A., Durrant, B. P., Fleurdepine, S., Harlos, K., Norbury, C. J., and Gilbert, R. J. (2015). Structural plasticity of Cid1 provides a basis for its distributive RNA terminal uridylyl transferase activity. Nucleic Acids Res. 43, 2968-2979. doi: $10.1093 /$ nar/gkv122

Yates, L. A., Fleurdepine, S., Rissland, O. S., De Colibus, L., Harlos, K., Norbury, C. J., et al. (2012). Structural basis for the activity of a cytoplasmic RNA terminal uridylyl transferase. Nat. Struct. Mol. Biol. 19, 782-787. doi: 10.1038/nsmb.2329

Yeo, J., and Kim, V. N. (2018). U-tail as a guardian against invading RNAs. Nat. Struct. Mol. Biol. 25, 903-905. doi: 10.1038/s41594-0180139-0

Zhu, H., Shyh-Chang, N., Segre, A. V., Shinoda, G., Shah, S. P., Einhorn, W. S., et al. (2011). The Lin28/let-7 axis regulates glucose metabolism. Cell 147, 81-94. doi: 10.1016/j.cell.2011.08.033

Conflict of Interest Statement: The authors declare that the research was conducted in the absence of any commercial or financial relationships that could be construed as a potential conflict of interest.

Copyright (c) 2018 Yashiro and Tomita. This is an open-access article distributed under the terms of the Creative Commons Attribution License (CC BY). The use, distribution or reproduction in other forums is permitted, provided the original author(s) and the copyright owner(s) are credited and that the original publication in this journal is cited, in accordance with accepted academic practice. No use, distribution or reproduction is permitted which does not comply with these terms. 